\title{
Grain Yield Performance of Hybrid Rice in Multi-Environment Tests for Thirty-two Years in India
}

KALAMBUR MURALIDHARAN ( $\nabla$ muralidharan_km@yahoo.com )

ICAR - IIRR: Indian Institute of Rice Research https://orcid.org/0000-0001-5008-1695

Gogineni S. V. Prasad

ICAR - IIRR: Indian Institute of Rice Research

Chilukuri S. Rao

ICAR - IIRR: Indian Institute of Rice Research

Ranganathan Sridhar

ICAR-National Rice Research Institute

Ebrahim A. Siddiq

ICAR - IIRR: Indian Institute of Rice Research

Original article

Keywords: Variety, Inbred rice, Hybrid rice, Heterosis, Breeding, Genetic gain, Oryza, Grain yield, Hybrid seeds, Greenhouse gas emission

Posted Date: December 10th, 2020

DOI: https://doi.org/10.21203/rs.3.rs-122407/v1

License: @ (i) This work is licensed under a Creative Commons Attribution 4.0 International License. Read Full License 


\section{Abstract}

Background: Hybrid $\mathrm{F}_{1}$ genotypes with higher yields or improvement in other traits of economic value due to heterosis as compared to inbred local check varieties (ILCV), are identified and released as hybrid commercial varieties. We analyzed the yield data of 2070 hybrid $F_{1}$ genotypes with ILCV evaluated over 32 years (1988 to 2019) in 2376 multi-environment experiments executed at 102 locations in the irrigated ecosystem across India.

Results: The genetic gain or loss in yield of hybrid $\mathrm{F}_{1}$ genotypes estimated over the test duration was non-significant. Hybrid $\mathrm{F}_{1}$ genotypes produced $10 \%$ more grains $(728-2588 \mathrm{~kg} / \mathrm{ha})$ than ILCV in many experiments at several locations. Our analyses have established that grain yields of 7.0 to $7.9 \mathrm{t} /$ ha, were harvested in hybrid $\mathrm{F}_{1}$ genotypes with early, mid-early and medium maturity duration, and in those with medium slender grains at many locations in 362 experiments. A higher level of rice productivity per day (62 to $63 \mathrm{~kg} / \mathrm{ha}$ ) was recorded with the early maturing and mid-early maturing hybrid $\mathrm{F}_{1}$ genotypes in these tests. The $\mathrm{N}$ requirement to produce $8 \mathrm{t} / \mathrm{ha}$ of hybrid rice grains was $15 \mathrm{~kg} \mathrm{~N} / \mathrm{t}$ as compared with a minimum of $20 \mathrm{~kg}$ $\mathrm{N} / \mathrm{t}$ used in China. Both the hybrids and inbreds in these experiments produced grain yields that were easily attained previously with high yielding ( $\geq 10 \mathrm{t} / \mathrm{ha}$ ) commercial inbreds since 1968. Unless the attainable yields are reached in inbred checks with the proven appropriate crop production practices in an experiment, it is futile to estimate a genetic gain or loss for grain yields in new genotypes developed.

Conclusions: Hybrid genotypes bred in India produced yields of 7 to $8 \mathrm{t} /$ ha which matched with reports from China on hybrids and green super rice; these India-bred hybrids showed higher productivity per day and shorter maturity periods than super hybrids of China. Opportunities still exist to breed indica/japonica hybrids to obtain more heterotic early and mid-early maturing hybrids, and develop efficient agronomical practices to realize the potential advantages from hybrids. There is scope for breeders to limit test locations to represent specific target areas to avoid data loss. Focusing on removing obstacles in hybrid seed production is essential to exploit yield heterosis in hybrids, and to make hybrid rice technology profitable to farmers.

\section{Background}

Heterosis or hybrid vigour is the increased function of any biological quality like biomass or grain yield in a hybrid offspring $\left(F_{1}\right)$ due to enhanced trait expression as a result of combined genetic contributions of its parents. Hybrid vigour for grain yield has been commercially exploited in many open-pollinated and often cross-pollinated crop plants using genetic or cytoplasmicgenetic male sterility systems for hybrid seed production. Rice is a self-pollinated crop, which makes it difficult to hybridize to produce a large $F_{1}$ population. A wild abortive (WA) cytoplasm was located in Hainan, China as a natural mutation of a wild rice (Oryza sativa f.sp. spontanea) that was developed into a cytoplasmic male sterile (CMS) genotype ${ }^{1}$. Exploitation of hybrid heterosis (10 to $20 \%$ higher grains than parents) in commercial rice production started when the essential genetic resources of the three-line system were successfully developed ${ }^{1-3}$. The commercial hybrid seed is produced by pollinating the CMS line with its corresponding maintainer line to generate more CMS seeds, and by hybridizing with restorer line to produce commercial $F_{1}$ hybrid seeds. Hybrids were shown to exhibit significant heterosis and heterobeltiosis (increased function in $F_{1}$ genotypes over better parent) for total dry matter and harvest index ${ }^{4}$. Hybrid rice was recognized in the socio-political environment of China as the most readily adoptable technology to increase the production level of rice. But the grain quality of these hybrids was unacceptable to Indian consumers and so lacked marketability in India. Therefore, the Indian Council of Agricultural Research (ICAR) launched a national program for the development of suitable hybrids in December 1987. This program was further strengthened with the technical support from the International Rice Research Institute (IRRI), Philippines, and financial support from the Food and Agriculture Organization (FAO), the United Nations Development Fund (UNDP), Maharashtra Hybrid Seeds Company Private Limited (Mahyco), the World Bank, and the IRRI and Asian Development Bank (ADB) consortium. 
In the dynamic hybrid rice-breeding program, hybrid genotypes with improvement in yields or in other traits of economic value, when compared with inbred local check variety (ILCV) are identified through phenotype-based selection and released for commercial cultivation. Each year hybrid $\mathrm{F}_{1}$ genotypes (hybrid genotypes) with improvement in yields over ILCV are assessed by All India Coordinated Project (AICRIP) in nationally coordinated multi-environment tests (METs) in the irrigated ecosystem

${ }^{5}$. During the evaluation of hybrid genotypes, yield, grain quality and resistance to biotic and abiotic stresses are ranked. The grain yield of hybrid genotypes that are superior because they yield 10\% more grains, in comparison with ILCV, is a decisive factor for primary selection in the METs. The mean grain yields of the top-three hybrid genotypes (T3HM), inbred local check variety (ILCVM) and hybrid $\mathrm{F}_{1}$ breeding stock or experimental mean (EXPM) represent the hypothetical floating checks of Jensen $^{6}$ that adjust to yield gains, if any, annually. Many inbred genotypes developed at the breeding centers in the country have been assessed for their yield performance in the METs of AICRIP during 1974-1994.The analysis of three floating checks showed a significant and positive annual increase in yields of $1.2 \%$ or $52 \mathrm{~kg} / \mathrm{ha}$ in inbred genotypes developed for the irrigated ecosystem ${ }^{7}$. ANOVA and regression analyses with and without environmental effects ${ }^{8}$ by deducting the check or experimental mean from the mean yield of the top-three genotypes to estimate differences and gain in yield over time, revealed no evidence for either a genetic gain or loss in grain yields of inbred genotypes from 1974 till 1994 ${ }^{7}$. The observed gain in yield has been attributed to improved crop-husbandry skills and farm infrastructure development at test locations over the years. The absence of any genetic gain for yields has also been demonstrated in inbred genotypes tested in 11 different rice ecosystems from 1995 to $2013^{9}$. Such an absence of genetic gain in yields was proved in similar analyses performed earlier on the grain yield of inbred rice genotypes developed by breeders and tested in worldwide experiments from 1976 to 1997 in the International Rice Testing Program (IRTP) - later termed as International Network for Genetic Evaluation of Rice (INGER) by the IRRI in different ecosystems ${ }^{10,11}$. The three floating checks in these international trials in the irrigated ecosystem showed non-significant annual grain yield increases of $16-18 \mathrm{~kg} / \mathrm{ha}$. The lack of progress in grain yield of inbred genotypes over the years was more or less similar in the national (AICRIP) and international (IRRI) testing programs ${ }^{7,10,11}$. We examined the realization of attributed yield advantage due to heterosis in the hybrid $\left(\mathrm{F}_{1}\right)$ genotypes developed using three-line system through an intensive national breeding program during the 32-year period from 1988 to 2019 using the same methods employed in earlier studies ${ }^{7,9,11}$.

\section{Results}

\section{Comparison of mean grain yields of hybrid genotypes in experiments}

Data sets on grain yield assessment of hybrid $F_{1}$ genotypes along with inbred LCV in 2376 experiments executed between 1988 and 2019 were used for this study (Table 1).

Table 1 Particulars of hybrid $\left(F_{1}\right)$ genotypes and inbred checks in IHRT experiments of AICRIP (1988 and 2019)\#

\begin{tabular}{|lllllll|}
\hline IHRT* & \multicolumn{2}{c}{ Hybrid $\mathrm{F}_{\mathbf{1}}$ genotypes } & Locations & \multicolumn{2}{l|}{ Years tested } & \multicolumn{2}{c|}{ Experiments performed } \\
& Total (No.) & Range & (No.) & (No.) & Range & Total (No.) \\
\hline IHRT-E (110-120 days) & 466 & $7-34$ & 84 & 26 & $6-46$ & 661 \\
\hline IHRT-ME (121-130 days) & 739 & $10-45$ & 82 & 29 & $5-35$ & 671 \\
\hline IHRT-MED (131-140 days) & 655 & $8-36$ & 83 & 30 & $5-37$ & 689 \\
\hline IHRT-MS (130 5 days) & 210 & $8-29$ & 68 & 14 & $18-33$ & 355 \\
\hline Grand Total & 2070 & & 102 & & & 2376 \\
\hline
\end{tabular}


\# Source data are provided in Additional file 1: Table S1-Sheet 1. \#IHRT = Initial hybrid rice trial; IHRT-E with early maturity (no test in 1988, 1989, 1990, 1992, 1996 and 1999; IHRT-ME with mid-early maturity (no test in 1988, 1989 and 1990); IHRT-MED with medium maturity (no test in 1990 and 1992) and IHRT-MS with medium slender grains (no test in1988 to 2005) groups. AICRIP = All-India coordinated rice improvement project

A comparison was done between the grain yields produced by hybrid genotypes in four Initial Hybrid Rice Trials (IHRT) with early (IHRT-E 110-120 days), mid-early (IHRT-ME 121-130 days), medium (IHRT-MED 131-140 days) maturity periods, and an exclusive group with medium slender grains (IHRT-MS $130 \pm 5$ days) (Table 2, Fig 1-2). The overall grain yields of T3HM in IHRT-E (110-120 days) were significantly higher $(P \leq 0.01)$ than those of the EXPM (by $761 \mathrm{~kg} / \mathrm{ha}$ ) or the ILCVM (by 1369 $\mathrm{kg} / \mathrm{ha}$ ). The EXPM was significantly $(P \geq 0.01)$ higher than that of ILCVM (by $608 \mathrm{~kg} / \mathrm{ha}$ ) (Table 2). The linear regression models on the three floating checks over the years showed non-significant annual yield increases of $5 \mathrm{~kg} / \mathrm{ha}$ in T3HM and 11 $\mathrm{kg} / \mathrm{ha}$ in EXPM. The ILCVM however, showed a highly significant $(P \geq 0.01)$ annual decrease of $41 \mathrm{~kg} / \mathrm{ha}$ in this maturity group trial (Fig. 1). The coefficients of determination for these three floating checks $\left(R^{2}, 0.008,0.080\right.$ and 0.303 , respectively) were very low and non-significant. In IHRT-ME (121-130 days), the overall grain yields of T3HM were significantly higher ( $P \leq$ 0.01) than the EXPM (by $802 \mathrm{~kg} / \mathrm{ha}$ ) or the ILCVM (by $992 \mathrm{~kg} / \mathrm{ha}$ ) (Table 2).

Table 2 Comparison of mean grain yields ( $\mathrm{kg} / \mathrm{ha}$ ) and variance among the three floating checks in AICRIP experiments (1988 and 2019)\# 


\begin{tabular}{|c|c|c|c|c|c|}
\hline \multirow[t]{2}{*}{ Particulars* } & \multicolumn{3}{|l|}{ Floating checks } & \multirow[t]{2}{*}{ LSD } & \multirow[t]{2}{*}{ CV (\%) } \\
\hline & $\begin{array}{l}\text { Top3 } F_{1} \text { genotype } \\
\text { mean }(T 3 H M)\end{array}$ & Experimental mean (EXPM) & $\begin{array}{l}\text { Inbred local check } \\
\text { mean (ILCVM) }\end{array}$ & & \\
\hline \multicolumn{6}{|c|}{ IHRT-E (Early maturing 110-120 days) } \\
\hline Grain yield (kg/ha) & 6211 & 5450 & 4842 & 274.43 & 6.67 \\
\hline Variance & 139286 & 86251 & 313392 & & \\
\hline ТЗНМ & - & $1.61^{\mathrm{NS}}$ & $0.44^{*}$ & & \\
\hline EXPM & $8.15^{\star \star}$ & - & $0.28 * \star$ & & \\
\hline ILCVM & $10.37 * \star$ & $4.90 * \star$ & - & & \\
\hline \multicolumn{6}{|c|}{ IHRT-ME (Mid-early maturing 121-130 days) } \\
\hline Grain yield (kg/ha) & 6527 & 5725 & 5534 & 161.94 & 3.87 \\
\hline Variance & 42463 & 61372 & 106978 & & \\
\hline ТЗНM & - & $0.69^{N S}$ & $0.40 * *$ & & \\
\hline EXPM & $13.38 * \star$ & - & $0.57^{\mathrm{NS}}$ & & \\
\hline ILCVM & $13.81^{\star *}$ & $2.49 * \star$ & - & & \\
\hline \multicolumn{6}{|c|}{ IHRT-MED (Medium maturing 131-140 days) } \\
\hline Grain yield (kg/ha) & 6277 & 5534 & 5407 & 251.85 & 5.9 \\
\hline Variance & 167975 & 162485 & 127712 & & \\
\hline ТЗНМ & - & $1.03^{N S}$ & $1.32^{\mathrm{NS}}$ & & \\
\hline EXPM & $7.06^{\star *}$ & - & $1.27^{\mathrm{NS}}$ & & \\
\hline ILCVM & $8.74 \star \star$ & $1.28^{\mathrm{NS}}$ & - & & \\
\hline \multicolumn{6}{|c|}{ IHRT-MS (Medium slender grains $130 \pm 5$ days) } \\
\hline Grain yield (kg/ha) & 6036 & 5456 & 5064 & 138.34 & 3.25 \\
\hline Variance & 39013 & 27491 & 62014 & & \\
\hline ТЗНM & - & $1.42^{\mathrm{NS}}$ & $0.63^{N S}$ & & \\
\hline EXPM & $8.41^{\star \star}$ & - & $0.44^{\mathrm{NS}}$ & & \\
\hline ILCVM & $11.43^{\star \star}$ & $4.89 * \star$ & - & & \\
\hline
\end{tabular}

Source data are provided in Additional file 1: Table S1-Sheet 1. " $I H R T=$ Initial hybrid rice trial; IHRT-E (no test in 1988, 1989, 1990, 1992, 1996 and 1999; IHRT-ME (no test in 1988, 1989 and 1990); IHRT-MED (no test in 1990 and 1992) and IHRT-MS (no test in1988 to 2005) groups. AICRIP = All-India coordinated rice improvement project; LSD = Least significant difference; Upper diagonal values represent $F$-values and lower diagonal values represent $t$-value; $N S=$ non-significant; ${ }^{*} P=0.05 ; \star \star P=0.01$.

The EXPM yield was also significantly higher than that of ILCVM (by $191 \mathrm{~kg} / \mathrm{ha}$ ). The linear regression models on the three floating checks over the years showed non-significant annual yield increases of $5 \mathrm{~kg} / \mathrm{ha}$ in T3HM, and $16 \mathrm{~kg} / \mathrm{ha}$ in ILCVM. The 
coefficients of determination values $\left(R^{2}, 0.035\right.$ and 0.176$)$ were very low and non-significant. Strangely, there was a significant increase of $21 \mathrm{~kg} / \mathrm{ha}$ in EXPM $\left(R^{2}, 0.540, R_{a}{ }^{2}, 0.523, P \leq 0.01, \mathrm{MSE}, 171\right)$ in this mid-early maturity group trial (Fig. 1). In IHRTMED (131-140 days), the overall grain yields of T3HM were significantly higher $(P \leq 0.01)$ than those of the EXPM by 742 $\mathrm{kg} / \mathrm{ha}$ or ILCVM by $869 \mathrm{~kg} / \mathrm{ha}$ (Table 2). The EXPM was higher than ILCVM by $127 \mathrm{~kg} / \mathrm{ha}$ but statistically on par with it. The linear regression models on the three floating checks over the years showed significant yearly yield increases of $29 \mathrm{~kg} / \mathrm{ha}$ in T3HM $(P=0.05), 35 \mathrm{~kg} / \mathrm{ha}$ in EXPM $(P=0.01)$ and $24 \mathrm{~kg} / \mathrm{ha}$ in ILCVM $(P=0.05)$ in this maturity group trial (Fig.2). The coefficients of determination were significant for these three floating checks $\left(R^{2}=0.378,0.568\right.$ and 0.371 , respectively). But the $R_{a}{ }^{2}$ was non-significant for ILCVM. In IHRT-MS (130 \pm 5 days), the overall grain yields of T3HM were significantly higher $(P$ $\leq 0.01$ ) than those of EXPM by $580 \mathrm{~kg} / \mathrm{ha}$ or ILCVM by $972 \mathrm{~kg} / \mathrm{ha}$ (Table 2). The EXPM was also higher than ILCVM by 392 $\mathrm{kg} / \mathrm{ha}$. The linear regression models on the three floating checks over the years showed significant $(P=0.05)$ yearly decreases of $37 \mathrm{~kg} / \mathrm{ha}$ in yields of T3HM, $29 \mathrm{~kg} / \mathrm{ha}$ in EXPM and $46 \mathrm{~kg} / \mathrm{ha}$ in ILCVM grain yields $\left(R^{2}, 0.605,0.525\right.$ and 0.584 , respectively) in this trial (Fig. 2). The adjusted coefficients of determination values were also significant $(P=0.05)$ for T3HM $\left(R_{a}{ }^{2}, 0.571, \mathrm{MSE}, 129\right)$ and ILCVM $\left(R_{a}{ }^{2}, 0.550, \mathrm{MSE}, 167\right)$. Yet the observed annual deviations in T3HM in IHRT-MED and IHRTMS are non-significant based on the linear models developed for the genetic gain derived by subtracting year-wise yield of EXPM or ILCVM from the yield of T3HM (Fig. 2). It is therefore clear that there is no genetic gain or loss in any of the hybrid $F_{1}$ genotypes with varying maturity duration or grain type developed during the 32-year period from 1988 to 2019.

\section{Grain types of the hybrid genotypes developed}

In each of the maturity group trials, we detected four major grain types in hybrid $F_{1}$ genotypes ${ }^{5}$ : long bold (kernel length $>6$ $\mathrm{mm}$, and length: breadth ratio (L/B) of <3.0); long slender (kernel length $>6 \mathrm{~mm}$, and L/B of $>3.0$ ); medium slender (kernel length $<6 \mathrm{~mm}$, and L/B of $2.5-3.0$ ); and short bold (kernel length $<6 \mathrm{~mm}$, and L/B of <2.5) (Additional file 4, Table S2). Hybrid $F_{1}$ genotypes with the consumer preferred medium slender grains (kernel length $<6 \mathrm{~mm}$, and L/B of $2.5-3.0$ ) were present in different maturity group trials that exactly matched in number with those in medium slender trial (181). Hybrid $F_{1}$ genotypes with short slender grains (kernel length $<6 \mathrm{~mm}$, and L/B of $>3.0$ ) have also been found in different maturity trials except in early maturing (<120 days) trial.

\section{Performance of hybrids across the country}

Hybrid $F_{1}$ genotypes with different maturity periods and those with medium slender grains were assessed for grain yields in tests for only 1-4 years in 270 experiments executed between 1988 and 2019 (Table 3). These data sets were inadequate to control error degrees of freedom in analysis ${ }^{12}$. Mean grain yields in the remaining data set from 1947 experiments executed at different locations for 5-24 years, were used for analysis (Additional file 1, Table S1). Further scrutiny indicated that hybrid $\mathrm{F}_{1}$ genotypes recorded lower mean grain yields than inbred checks over the years in 962 experiments and were well-distributed in IHRT-E (286), IHRT-ME (218), IHRT-MED (316) and IHRT-MS (142 experiments) (Table 3). Only the data from 985 experiments showed higher yields of hybrid $\mathrm{F}_{1}$ genotypes than inbred checks at several locations and in one or more trials.

\section{Table 3 Available data on the experiments at locations across India to test hybrid $F_{1}$ genotypes in IHRT trials in AICRIP (1988 and 2019)\#}




\begin{tabular}{|c|c|c|c|c|c|c|}
\hline Experiments at a location & $\begin{array}{l}\text { IHRT - } \\
\text { E }\end{array}$ & $\begin{array}{l}\text { IHRT- } \\
\text { ME }\end{array}$ & $\begin{array}{l}\text { IHRT- } \\
\text { MED }\end{array}$ & $\begin{array}{l}\text { IHRT- } \\
\text { MS }\end{array}$ & \multicolumn{2}{|c|}{$\begin{array}{l}\text { Total } \\
\text { experiments* }\end{array}$} \\
\hline (No.) & & & & & (No.) & $(\%)$ \\
\hline 1-Year & 21 & 21 & 19 & 18 & 79 & 3.56 \\
\hline 2-Year & 16 & 20 & 20 & 14 & 70 & 3.16 \\
\hline 3-Year & 18 & 18 & 27 & 6 & 69 & 3.11 \\
\hline 4-Year & 20 & 12 & 4 & 16 & 52 & 2.35 \\
\hline 1 to 4 -year total & 75 & 71 & 70 & 54 & 270 & 12.18 \\
\hline 5 to 24-year total & 596 & 460 & 572 & 319 & 1947 & 87.82 \\
\hline Grand total & 671 & 531 & 642 & 373 & 2217 & 100 \\
\hline \multicolumn{7}{|l|}{ Experiments for 5 to 24-year } \\
\hline $\begin{array}{l}\emptyset \text { Above inbred local or hybrid check variety } \\
(\mathrm{ILCV} / \mathrm{HCV})\end{array}$ & 310 & 242 & 256 & 177 & 985 & 44.43 \\
\hline \multirow[t]{2}{*}{$\varnothing$ Below inbred local check variety (ILCV) } & 286 & 218 & 316 & 142 & & \\
\hline & & & & & 962 & 43.39 \\
\hline
\end{tabular}

\#Source data are provided in Additional file 1: Table S1-Sheet 2. *Due to ambiguity in nomenclature of some locations in the initial years, data from 159 experiments were removed before analyses. ${ }^{\text {IHRT }}$ = Initial hybrid rice trial; IHRT-E (Early maturity 110-120 days), IHRT-ME (Mid-early maturity 121-130 days), IHRT-MED (Medium maturity 131-140 days) and IHRT-MS (Medium slender grains, maturity $130 \pm 5$ days); AICRIP = All-India coordinated rice improvement project. Computed mean grain yields of commercial hybrid used as HCV (only from 1996) or inbred local check variety (ILVC) used across all locations in each year included for a comparison with hybrid $\left(\mathrm{F}_{1}\right)$ genotypes tested.

Hybrid $F_{1}$ genotypes performed poorly in comparison with inbred LCV at 28 (22 AICRIP, 1 private and 5 voluntary) locations (Additional file 5, Table S3). The mean yields of hybrid $F_{1}$ genotypes tested in 52 experiments were the lowest (from 3.2 to 3.9 $\mathrm{t} / \mathrm{ha}$ ) at Bhubaneswar in Odisha state, in contrast to the overall mean yields of ILCVM (5.0 to $5.7 \mathrm{t} / \mathrm{ha}$ ). The grain yields of genotypes at these locations, over the years in experiments recorded yields lower than ILCVM by 498-2146 kg/ha in IHRT-E, $154-2395 \mathrm{~kg} / \mathrm{ha}$ in IHRT-ME, 84-2290 kg/ha in IHRT-MED and 74-1125 kg/ha in IHRT-MS trials. The highest yields recorded were 7 to $7.7 \mathrm{t} / \mathrm{ha}$ at 13 locations and 6 to $6.5 \mathrm{t} / \mathrm{ha}$ in nine other locations.

\section{Mean grain yield of hybrid $F_{1}$ genotypes higher than inbred check}

Hybrid $F_{1}$ genotypes with early maturity (110-120 days) produced higher grain yields than ILCV at 22 locations in 309 experiments (Table 4). In the analysis of variance, the $F$-value showed highly significant $(P<0.01)$ differences in the mean grain yields of locations compared with ILCV. The yields achieved in hybrid $F_{1}$ genotypes were within the hypothesized $10 \%$ extra grain yield over ILCV due to heterosis at four AICRIP and two voluntary locations. The early maturing hybrid $\mathrm{F}_{1}$ genotypes showed higher yields by $664-2031 \mathrm{~kg} / \mathrm{ha}$ than ILCV, and by $75-1442 \mathrm{~kg} / \mathrm{ha}$ than hybrid commercial variety (HCV) at 16 other (9 private funded, 5 AICRIP and 2 voluntary) locations. The ILCV registered only $5.2 \mathrm{t} / \mathrm{ha}$ in this trial. The hybrid genotypes showed mean grain yields ranging from 7.0 to $7.4 \mathrm{t} / \mathrm{ha}$ at seven locations in two statistically significant groups. The grain productivity per day varied from 61 to $63 \mathrm{~kg} / \mathrm{ha}$ at these locations. 
Table 4 Grain yield of hybrid $F_{1}$ genotypes higher than the yield of ILCV or HCV in IHRT-E (110-120 days)experiments (5-24 years) in AICRIP (1988 and 2019)\#

\begin{tabular}{|c|c|c|c|c|c|c|c|}
\hline \multirow[t]{2}{*}{ No. } & \multirow[t]{2}{*}{ Location } & \multirow[t]{2}{*}{ Funding* } & \multirow[t]{2}{*}{ Experiments } & \multicolumn{3}{|c|}{ Grain yield (kg/ha) } & \multirow{2}{*}{$\begin{array}{l}\text { Productivity } \\
\text { (kg/ha/day) }\end{array}$} \\
\hline & & & & Meant & Over ILCV & Over HCV & \\
\hline 1 & Mahyco Seeds & Private & 13 & $7276 a$ & 2031 & 1442 & 63 \\
\hline 2 & Bio Seeds & Private & 7 & $7169 a$ & 1924 & 1335 & 62 \\
\hline 3 & Mandya & AICRIP & 23 & 7137a & 1893 & 1303 & 62 \\
\hline 4 & Bayer & Private & 12 & $7125 b$ & 1880 & 1291 & 62 \\
\hline 5 & Syngenta India & Private & 8 & $7121 b$ & 1877 & 1287 & 62 \\
\hline 6 & Advanta & Private & 15 & $7022 b$ & 1777 & 1188 & 61 \\
\hline 7 & Karnal & AICRIP & 14 & $7011 b$ & 1766 & 1177 & 61 \\
\hline 8 & Parry Monsanto & Private & 5 & $6937 c$ & 1693 & 1103 & 60 \\
\hline 9 & Kaul & AICRIP & 9 & $6895 c$ & 1651 & 1061 & 60 \\
\hline 10 & Coimbatore & AICRIP & 22 & $6719 c$ & 1475 & 885 & 58 \\
\hline 11 & HR International & Private & 9 & $6669 c$ & 1425 & 835 & 58 \\
\hline 12 & Ludhiana & Private & 16 & $6639 c$ & 1395 & 805 & 58 \\
\hline 13 & VNR Seeds & Private & 11 & $6441 d$ & 1197 & 607 & 56 \\
\hline 14 & Gaddipally & Voluntary & 6 & $6399 d$ & 1154 & 565 & 56 \\
\hline 15 & Jabalpur & Voluntary & 16 & $6203 e$ & 958 & 369 & 54 \\
\hline 16 & Kapurthala & AICRIP & 5 & $5909 f$ & 664 & 75 & 51 \\
\hline \multicolumn{3}{|c|}{ Hybrid check variety (HCV) } & 17 & $5834 f$ & 589 & 0 & 51 \\
\hline 17 & Warangal & AICRIP & 15 & $5755 f$ & 510 & & 50 \\
\hline 18 & Navasari & AICRIP & 8 & $5747 f$ & 503 & & 50 \\
\hline 19 & Aduthurai & AICRIP & 17 & $5688 f$ & 443 & & 49 \\
\hline 20 & Nawagam & AICRIP & 18 & $5640 f$ & 395 & & 49 \\
\hline 21 & Karaikal & Voluntary & 9 & $5513 \mathrm{~g}$ & 269 & & 48 \\
\hline 22 & Vadgaon & Voluntary & 10 & $5509 \mathrm{~g}$ & 265 & & 48 \\
\hline \multicolumn{3}{|c|}{ Inbred local check variety (ILCV) } & 24 & $5245 h$ & 0 & & 46 \\
\hline \multicolumn{3}{|c|}{ CV (\%) } & & 10.10 & & & \\
\hline
\end{tabular}

\#Source data are provided in Additional file 1: Table S1-Sheet 2. \#ILCV = inbred local check; HCV = hybrid commercial variety (used only from 1996). *AICRIP (All-India coordinated rice improvement project) - public funded, Private - seed industry funded, and Voluntary - partially public funded. TDMRT computed based on unequal replications. Any two means followed by a common alphabet are not significantly different at $P=0.05$. $\mathrm{CV}=$ Coefficient of variation 
Hybrid $F_{1}$ genotypes with mid-early maturity (121-130 days) produced higher grain yields than ILCV at 21 locations in 242 experiments (Table 5). In the analysis of variance, the $F$-value showed highly significant $(P<0.01)$ differences in the mean grain yields of locations compared with ILCV. The yields achieved in hybrid $\mathrm{F}_{1}$ genotypes were within the hypothesized $10 \%$ extra grain yield over ILCV due to heterosis at three AICRIP, one private and one voluntary location, besides HCV. Thirteen locations were in four distinct statistically significant groups. Hybrid genotypes showed higher yields by $980-2130 \mathrm{~kg} / \mathrm{ha}$ than ILCV, and by $641-1791 \mathrm{~kg} / \mathrm{ha}$ than HCV. The ILCV registered only $5.7 \mathrm{t} / \mathrm{ha}$ in this trial. The hybrid genotypes showed mean grain yields ranging from 7.1 to $7.9 \mathrm{t} / \mathrm{ha}$ at nine (4 AICRIP and 5 private funded) locations in three statistically significant groups. The grain productivity per day varied from 57 to $63 \mathrm{~kg} / \mathrm{ha}$ at these locations.

Table 5 Grain yield of hybrid $F_{1}$ genotypes higher than the yield of ILCV or HCV in IHRT-ME (121-130 days)experiments (5-24 years) in AICRIP (1988 and 2019)\# 


\begin{tabular}{|c|c|c|c|c|c|c|c|}
\hline \multirow[t]{2}{*}{ No. } & \multirow[t]{2}{*}{ Location } & \multirow[t]{2}{*}{ Funding* } & \multirow[t]{2}{*}{ Experiments } & \multicolumn{3}{|c|}{ Grain yield (kg/ha) } & \multirow{2}{*}{$\begin{array}{l}\text { Productivity } \\
\text { (kg/ha/day) }\end{array}$} \\
\hline & & & & Meant & Over ILCV & Over HCV & \\
\hline 1 & Nuziveedu Seeds & Private & 6 & $7874 a$ & 2130 & 1791 & 63 \\
\hline 2 & Mandya & AICRIP & 18 & $7661 a$ & 1917 & 1578 & 61 \\
\hline 3 & Syngenta India & Private & 9 & $7532 b$ & 1788 & 1449 & 60 \\
\hline 4 & Karnal & AICRIP & 11 & $7408 b$ & 1663 & 1324 & 59 \\
\hline 5 & Mahyco Seeds & Private & 14 & $7395 b$ & 1650 & 1312 & 59 \\
\hline 6 & Bayer & Private & 10 & $7374 b$ & 1630 & 1291 & 59 \\
\hline 7 & Coimbatore & AICRIP & 19 & $7225 c$ & 1480 & 1142 & 58 \\
\hline 8 & Kaul & AICRIP & 7 & $7141 c$ & 1397 & 1058 & 57 \\
\hline 9 & Parry Monsanto & Private & 5 & $7098 c$ & 1354 & 1015 & 57 \\
\hline 10 & Ludhiana & AICRIP & 12 & $6870 d$ & 1126 & 787 & 55 \\
\hline 11 & Mugad & AICRIP & 5 & $6784 d$ & 1039 & 701 & 54 \\
\hline 12 & HR International & Private & 9 & $6733 d$ & 989 & 650 & 54 \\
\hline 13 & Advanta & Private & 9 & $6724 d$ & 980 & 641 & 54 \\
\hline 14 & Kaveri Seeds & Private & 5 & $6585 e$ & 841 & 502 & 53 \\
\hline 15 & Bio Seeds & Private & 5 & $6412 e$ & 667 & 328 & 51 \\
\hline 16 & Jabalpur & Voluntary & 13 & $6348 e$ & 604 & 265 & 51 \\
\hline 17 & Gaddipally & Voluntary & 5 & $6283 e$ & 538 & 200 & 50 \\
\hline 18 & Aduthurai & AICRIP & 8 & $6170 e$ & 425 & 86 & 49 \\
\hline \multicolumn{3}{|c|}{ Hybrid check variety (HCV) } & 18 & $6083 e$ & 339 & 0 & 49 \\
\hline 19 & Nawagam & AICRIP & 16 & $5980 f$ & 236 & & 48 \\
\hline 20 & Warangal & AICRIP & 11 & $5887 \mathrm{~g}$ & 142 & & 47 \\
\hline 21 & VNR Seeds & Private & 8 & $5868 \mathrm{~g}$ & 123 & & 47 \\
\hline \multicolumn{3}{|c|}{ Inbred local check variety (ILCV) } & 19 & $5745 h$ & 0 & & 46 \\
\hline \multicolumn{3}{|c|}{ CV \%) } & & 9.87 & & & \\
\hline
\end{tabular}

\#Source data are provided in Additional file 1: Table S1-Sheet 2. \#ILCV - inbred local check; HCV - hybrid commercial variety (used only from 1996). *AICRIP (All-India coordinated rice improvement project) - public funded, Private - seed industry funded, and Voluntary - partially public funded. TDMRT computed based on unequal replications. Any two means followed by a common alphabet are not significantly different at $P=0.05$. CV $=$ Coefficient of variation

Hybrid $F_{1}$ genotypes with medium maturity (131-140 days) recorded higher grain yields than ILCV at 18 locations in 256 experiments (Table 6). In the analysis of variance, the $F$-value showed highly significant $(P<0.01)$ differences in the mean grain yields of locations compared with ILCV. The yields achieved in hybrid $\mathrm{F}_{1}$ genotypes were within the hypothesized $10 \%$ extra grain yield over ILCV due to heterosis at two (1 private funded and 1 voluntary) locations and HCV. Hybrid genotypes showed higher yields $656-2184 \mathrm{~kg} / \mathrm{ha}$ than ILCV, and by $118-1646 \mathrm{~kg} / \mathrm{ha}$ than HCV at 16 other (6 AICRIP funded, 9 private 
funded and 1 voluntary) locations. The ILCV registered only $5.7 \mathrm{t} /$ ha in this trial. The hybrid genotypes showed mean grain yields ranging from 7.0 to $7.9 \mathrm{t} / \mathrm{ha}$ at 11 locations. The grain productivity per day varied from 52 to $58 \mathrm{~kg} / \mathrm{ha}$ at these locations.

Table 6 Grain yield of hybrid $F_{1}$ genotypes higher than the yield of ILCV or HCV in IHRT-MED (131-140 days)experiments (5-24 years) in AICRIP (1988 and 2019)\#

\begin{tabular}{|c|c|c|c|c|c|c|c|}
\hline \multirow[t]{2}{*}{ No. } & \multirow[t]{2}{*}{ Location } & \multirow[t]{2}{*}{ Funding* } & \multirow[t]{2}{*}{ Experiments } & \multicolumn{3}{|c|}{ Grain yield (kg/ha) } & \multirow{2}{*}{$\begin{array}{l}\text { Productivity } \\
\text { (kg/ha/day) }\end{array}$} \\
\hline & & & & Meant & Over ILCV & Over HCV & \\
\hline 1 & Nuziveedu Seeds & Private & 7 & $7885 a$ & 2184 & 1646 & 58 \\
\hline 2 & Mahyco Seeds & Private & 12 & $7746 a$ & 2045 & 1507 & 57 \\
\hline 3 & Bayer & Private & 13 & $7628 b$ & 1928 & 1390 & 57 \\
\hline 4 & HR International & Private & 7 & 7490b & 1789 & 1252 & 55 \\
\hline 5 & Karnal & AICRIP & 11 & $7462 c$ & 1761 & 1223 & 55 \\
\hline 6 & Kaul & AICRIP & 9 & $7297 c$ & 1596 & 1059 & 54 \\
\hline 7 & Mandya & AICRIP & 22 & $7086 d$ & 1385 & 848 & 52 \\
\hline 8 & Pan Seeds & Private & 5 & $7085 d$ & 1384 & 846 & 52 \\
\hline 9 & Coimbatore & AICRIP & 23 & $7062 d$ & 1361 & 823 & 52 \\
\hline 10 & Syngenta India & Private & 9 & $6995 d$ & 1294 & 757 & 52 \\
\hline 11 & Advanta & Private & 11 & $6961 e$ & 1260 & 722 & 52 \\
\hline 12 & Warangal & AICRIP & 14 & $6520 f$ & 819 & 282 & 48 \\
\hline 13 & Ludhiana & AICRIP & 16 & $6483 f$ & 782 & 245 & 48 \\
\hline 14 & Bio Seeds & Private & 8 & $6480 f$ & 779 & 241 & 48 \\
\hline 15 & Kaveri Seeds & Private & 5 & $6438 f$ & 737 & 200 & 48 \\
\hline 16 & Jabalpur & Voluntary & 16 & $6357 f$ & 656 & 118 & 47 \\
\hline \multicolumn{3}{|c|}{ Hybrid check variety (HCV) } & 23 & $6238 \mathrm{~g}$ & 538 & 0 & 46 \\
\hline 17 & VNR Seeds & Private & 10 & $6060 \mathrm{~h}$ & 359 & & 45 \\
\hline 18 & Allahabad & Voluntary & 12 & $6035 \mathrm{~h}$ & 334 & & 45 \\
\hline \multicolumn{3}{|c|}{ Inbred local check variety (ILCV) } & 23 & $5701 i$ & 0 & & \\
\hline \multicolumn{3}{|c|}{ CV (\%) } & & 9.97 & & & \\
\hline
\end{tabular}

\#Source data are provided in Additional file 1: Table S1-Sheet 2. \#ILCV - inbred local check; HCV - hybrid commercial variety (used only from 1996). *AICRIP (All-India coordinated rice improvement project) - public funded, Private - seed industry funded, and Voluntary - partially public funded. TDMRT computed based on unequal replications. Any two means followed by a common alphabet are not significantly different at $P=0.05$. CV $=$ Coefficient of variation 
Hybrid $F_{1}$ genotypes with medium slender grains ( $130 \pm 5$ days) recorded higher mean yields than ILCV at 15 locations in 177 experiments (Table 7). In the analysis of variance, the $F$-value showed highly significant $(P<0.01)$ differences in the mean grain yields of locations compared with ILCV. The yields achieved in hybrid $\mathrm{F}_{1}$ genotypes were within the hypothesized $10 \%$ extra grain yield over ILCV due to heterosis at four AICRIP locations. At 11 other (3 AICRIP, 5 private funded and 3 voluntary) locations, hybrid genotypes recorded higher yields by $828-2525 \mathrm{~kg} / \mathrm{ha}$ than ILCV and by $93-1789 \mathrm{~kg} / \mathrm{ha}$ than HCV. The ILCV registered only $5.0 \mathrm{t} / \mathrm{ha}$ in this trial. The hybrid genotypes showed mean grain yields ranging from 6.5 to $7.6 \mathrm{t} / \mathrm{ha}$ at seven locations in three statistically significant groups. The grain productivity per day varied from 49 to $57 \mathrm{~kg} / \mathrm{ha}$ at these locations.

Table 7 Grain yield of hybrid $F_{1}$ genotypes higher than the yield of ILCV or HCV in IHRT-MS (medium slender grains $130 \pm 5$ days)experiments (5-24 years) in AICRIP (1988 and 2019)\#

\begin{tabular}{|c|c|c|c|c|c|c|c|}
\hline \multirow[t]{2}{*}{ No. } & \multirow[t]{2}{*}{ Location } & \multirow[t]{2}{*}{ Funding* } & \multirow[t]{2}{*}{ Experiments } & \multicolumn{3}{|c|}{ Grain yield (kg/ha) } & \multirow{2}{*}{$\begin{array}{l}\text { Productivity } \\
\text { (kg/ha/day) }\end{array}$} \\
\hline & & & & Meant & Over ILCV & Over HCV & \\
\hline 1 & Mandya & AICRIP & 12 & $7559 a$ & 2525 & 1789 & 57 \\
\hline 2 & Kaveri Seeds & Private & 5 & 6964b & 1931 & 1195 & 53 \\
\hline 3 & Bayer & Private & 11 & 6951b & 1918 & 1182 & 53 \\
\hline 4 & Coimbatore & AICRIP & 12 & $6849 b$ & 1816 & 1080 & 52 \\
\hline 5 & Nuziveedu Seeds & Private & 9 & $6813 b$ & 1780 & 1044 & 52 \\
\hline 6 & Jabalpur & Voluntary & 12 & $6589 c$ & 1555 & 819 & 50 \\
\hline 7 & Advanta & Private & 8 & $6504 c$ & 1471 & 735 & 49 \\
\hline 8 & Warangal & AICRIP & 14 & $6073 d$ & 1040 & 304 & 46 \\
\hline 9 & Karaikal & Voluntary & 8 & $5893 d$ & 860 & 124 & 45 \\
\hline 10 & VNR Seeds & Private & 10 & $5879 \mathrm{e}$ & 846 & 110 & 45 \\
\hline 11 & Allahabad & Voluntary & 7 & $5862 e$ & 828 & 93 & 44 \\
\hline \multicolumn{3}{|c|}{ Hybrid check variety (HCV) } & 11 & $5769 \mathrm{e}$ & 736 & 0 & 44 \\
\hline 12 & Chinsurah & AICRIP & 13 & $5423 f$ & 390 & & 41 \\
\hline 13 & Cuttack & AICRIP & 6 & $5421 f$ & 387 & & 41 \\
\hline 14 & Karjat & AICRIP & 14 & $5378 f$ & 344 & & 41 \\
\hline 15 & Nawagam & AICRIP & 11 & $5192 \mathrm{~g}$ & 159 & & 39 \\
\hline \multicolumn{3}{|c|}{ Inbred local check variety (ILCV) } & 14 & $5033 \mathrm{~g}$ & 0 & & 38 \\
\hline \multicolumn{3}{|c|}{ CV (\%) } & & 10.90 & & & \\
\hline
\end{tabular}

\#Source data are provided in Additional file 1: Table S1-Sheet 2. \#HCV used only from 1996; IHRT-MS started from 2006; *AICRIP (All-India coordinated rice improvement project) - public funded, Private - seed industry funded, and Voluntary partially public funded. TDMRT computed based on unequal replications. Any two means followed by a common alphabet are not significantly different at $P=0.05$. $\mathrm{CV}=$ Coefficient of variation 
The performance of commercially released hybrid varieties (HCV) was compared with that of inbred checks (ILCV) in the respective experiments executed between 2005 and 2019 (Table 8). Ten commercially released hybrid varieties have been used as HCV in these experiments. The early maturing PSD1, mid-early maturing PA 6201 and US 212 and medium maturing KRH 2 hybrids did not produce 10\% more grains over the yield of ILCV. PSD3, PA 6129 and US 314 (early maturing), HRI 174 (mid-early maturing) and DRRH3 and JKRH 3333 (with medium slender grains)showed $10 \%$ more yields than that of ILCV.US 314 recorded the highest mean grain yields of $6.4 \mathrm{t} / \mathrm{ha}$ in 148 experiments. However, in many experiments these HCV produced $\geq 10 \mathrm{t} /$ ha grain yields. The highest yield record varied from 10.1 to $13.4 \mathrm{t} / \mathrm{ha}$ in 10 commercially released hybrids compared to ILCV that varied from 6.1 to $9.8 \mathrm{~kg} / \mathrm{ha}$. The productivity also showed variations; it varied from 41 to $56 \mathrm{~kg} / \mathrm{ha} \mathrm{per}$ day in commercially released HCV, and from 36 to $45 \mathrm{~kg} / \mathrm{ha}$ per day in ILCV. The highest productivity was in early maturing hybrid US 314. Compared with the use of 10 commercially released hybrid varieties, 54 commercially released inbred varieties have been used as ILCV (Supplementary Table 3). The mean grain yield varied in these ILCV also; it varied from 3.6 to $6.0 \mathrm{t} / \mathrm{ha}$ in early, from 3.8 to 7.4 t/ha in mid-early, and 4.1 to 7.9 t/ha in medium maturing ILCV, and from 4.5 to 5.0 t/ha in ILCV with medium slender grains. Nevertheless, several inbred varieties in many experiments produced high yields of 7 to 9 t/ha (Additional file 6, Table S4).

Table 8 Comparison of the performance of released hybrid commercial variety (HCV) with inbred local check variety (ILCV) in IHRT experiments in AICRIP (1988 and 2019)" 


\begin{tabular}{|c|c|c|c|c|c|c|c|c|c|}
\hline No. & $\begin{array}{l}\text { HCV (cross, year of } \\
\text { release)* }\end{array}$ & Experiments & $\begin{array}{l}\text { Highest } \\
\text { yield } \\
\text { (kg/ha) }\end{array}$ & $\begin{array}{l}\text { Mean } \\
\text { yield } \\
\text { (kg/ha) }\end{array}$ & $\begin{array}{l}F \\
\text { value }\end{array}$ & $P$-value & $\begin{array}{l}\text { CV } \\
(\%)\end{array}$ & $\begin{array}{l}\text { Over } \\
\text { ILCV }\end{array}$ & $\begin{array}{l}\text { Productivity } \\
\text { (kg/ha/day) }\end{array}$ \\
\hline & \multicolumn{9}{|c|}{ IHRT-E (110-120 days) } \\
\hline \multirow[t]{2}{*}{1} & $\begin{array}{l}\text { PSD1 (IR } \\
58025 A / U P R I ~ 92- \\
133,1997)\end{array}$ & 55 & 11172 & 5208 & 0.37 & 0.54338 & 19.80 & 118 & 45 \\
\hline & ILCV & 55 & 9483 & 5090 & & & & & 44 \\
\hline \multirow[t]{2}{*}{2} & $\begin{array}{l}\text { PSD3 (UPRI 95- } \\
\text { 17A/UPRI 92-287R, } \\
\text { 2004) }\end{array}$ & 56 & 11591 & 5570 & 9.26 & 0.00292 & 21.46 & 647 & 48 \\
\hline & ILCV & 56 & 9111 & 4923 & & & & & 43 \\
\hline \multirow[t]{2}{*}{3} & $\begin{array}{l}\text { PA 6129 } \\
(6 \mathrm{CO} 2 / 6 \mathrm{M} 10, \\
2007)\end{array}$ & 181 & 11827 & 5804 & 58.50 & $1.9 \mathrm{E}-13$ & 21.96 & 942 & 50 \\
\hline & ILCV & 181 & 9082 & 4862 & & & & & 42 \\
\hline \multirow[t]{3}{*}{4} & $\begin{array}{l}\text { US } 314 \\
\text { (F11/M4318, 2013) }\end{array}$ & 148 & 10101 & 6418 & 79.22 & $5.9 \mathrm{E}-17$ & 15.85 & 973 & 56 \\
\hline & ILCV & 148 & 6402 & 5445 & & & & & 47 \\
\hline & \multicolumn{9}{|c|}{ IHRT-ME (121-130 days) } \\
\hline \multirow[t]{2}{*}{5} & $\begin{array}{l}\text { PA 6201 } \\
(6 \mathrm{CO} 2 / 6 \mathrm{MO} 1 \\
2000)\end{array}$ & 261 & 12136 & 5798 & 18.40 & 2.1E-05 & & 390 & 46 \\
\hline & ILCV & 261 & 9300 & 5408 & & & & & 43 \\
\hline \multirow[t]{3}{*}{6} & $\begin{array}{l}\text { US } 312 \text { (F1/M66, } \\
2000)\end{array}$ & 208 & 12103 & 6147 & 22.10 & $3.5 \mathrm{E}-06$ & 18.33 & 499 & 49 \\
\hline & ILCV & 208 & 6130 & 5648 & & & & & 45 \\
\hline & IHRT-MED (131-140 & ays) & & & & & & & \\
\hline \multirow[t]{2}{*}{7} & $\begin{array}{l}\text { KRH } 2 \text { (IR } \\
59025 A / K M R 3 R, \\
1996)\end{array}$ & 267 & 10858 & 5837 & 15.50 & $9.4 \mathrm{E}-05$ & 18.32 & 353 & 43 \\
\hline & ILCV & 267 & 9768 & 5484 & & & & & 41 \\
\hline \multirow[t]{3}{*}{8} & $\begin{array}{l}\text { HRI } 174 \\
\text { (c112/mo13, 2015) }\end{array}$ & 154 & 13439 & 6500 & 55.39 & $1 \mathrm{E}-12$ & 16.61 & 855 & 48 \\
\hline & ILCV & 154 & 9752 & 5645 & & & & & 42 \\
\hline & IHRT-MS (130 \pm 5 da & & & & & & & & \\
\hline \multirow[t]{2}{*}{9} & $\begin{array}{l}\text { DRRH3(APMS } \\
\text { 6A/RPHR 1005, } \\
\text { 2009) }\end{array}$ & 193 & 10533 & 5394 & 40.60 & $5.4 \mathrm{E}-10$ & 18.87 & 622 & 41 \\
\hline & ILCV & 193 & 9677 & 4772 & & & & & 36 \\
\hline \multirow[t]{2}{*}{10} & $\begin{array}{l}\text { JKRH } 3333 \text { (JKRA } \\
\text { 1047/JKRR 10092, } \\
\text { 2012) }\end{array}$ & 76 & 12556 & 6180 & 100.58 & $2 \mathrm{E}-18$ & 15.75 & 1404 & 46 \\
\hline & ILCV & 76 & 7627 & 4776 & & & & & 36 \\
\hline
\end{tabular}


\#Source data ${ }^{5}{ }^{*}$ Commercial hybrid varieties used only from 2005-2019.

\section{Discussion}

Hybrid rice seeds are genetically packed to produce high yields due to heterosis. Seeds are also the most effective and inexpensive medium to transfer hybrid rice technology to farmers. Isolated evaluation reports on hybrid rice were biased and conclusions were based on insufficient data ${ }^{13,14}$. We have used the largest data generated on hybrid rice by AICRIP in METs ${ }^{5}$ for 32 years (Additional file 1: Table S1). Although the irrigated ecosystem is made homogenous by regular applications of water, environmental and yearly variations may influence the yields recorded at test locations. Therefore, yield data sets were statistically corrected suitably to neutralize the year effect as well as the location effect before any analysis. Further, the three floating checks namely T3HM, EXPM and ILCVM were used to remove pitfalls in estimating absolute yield performance. When similar trend is observed in the floating checks, the actual genetic gain or loss over years is obtained in the re-analysis by deducting year-wise experimental or check mean yield from the mean yield of top-three genotypes (Fig 1-2).

\section{Grain yields of hybrid genotypes}

The top-three hybrid genotypes in IHRT trials produced significantly higher grain yields than that of the experimental mean or the inbred check variety mean yields over the years and across locations evaluated (Table 2). Over 32 years (1988-2019), the grain yields of T3HM increased by 0.6 to $0.8 \mathrm{t} /$ ha than that of the EXPM and by 0.9 to $1.4 \mathrm{t} /$ ha than that of ILCVM. The EXPM of hybrid genotypes assessed was also higher by 0.1 to $0.6 \mathrm{t} /$ ha than that of the inbred LCVM (Table 2). The contention on yield advantage due to heterosis in hybrids was not apparently present in most of these hybrid $\mathrm{F}_{1}$ genotypes. The linear regression models on the three floating checks over the years showed significant annual increases of 5-29 kg/ha in T3HM and $11-34 \mathrm{~kg} / \mathrm{ha}$ in EXPM in early, mid-early and medium maturing hybrids. However, the mean grain yield of ILCV decreased in early maturing hybrids and those with medium slender grains by $41-46 \mathrm{~kg} / \mathrm{ha}$ but increased in mid-early and medium maturing hybrids by $16-24 \mathrm{~kg} / \mathrm{ha}$. The consumers in India are well-known to prefer and accept short bold or long slender grains. The stress on market preferred grain type rather than on the level of heterosis of hybrid $\mathrm{F}_{1}$ genotypes was the evident cause of such declining yields of floating checks in IHRT-MS trial over the years. The classical stability parameters often do not consider the absolute performance of genotype cohorts evaluated in experiments. A few statistical parameters were developed to combine both stability and performance ${ }^{6,15,16}$. The floating checks of Jensen ${ }^{6}$ however, combine both stability and performance ${ }^{17}$. The trend observed was more or less similar across the three floating checks studied using AICRIP experimental data. When a linear model showed a significant increase or decrease in T3HM, the environmental effects were eliminated in that data year-wise by deducting EXPM or ILCVM from T3HM. The linear models developed after removing environmental effects became statistically non-significant. Evidence thus obtained clearly revealed lack of genetic gain or loss in hybrid genotypes developed over the 32 years. Our analyses have established that grain yields of 7.0 to 7.9 t/ha were harvested in hybrid $\mathrm{F}_{1}$ genotypes with early, mid-early and medium maturity, and in those with medium slender grains at 20 locations and in 362 experiments performed during 1988 to 2019 (Tables 4-7).

\section{Disarray in the assessment of hybrids}

The assessment of hybrid genotype performance has generally been defining rather than experimenting with them due to following reasons. During 1988-2019, 102 locations were used to test 2070 hybrid $F_{1}$ genotypes in 2376 experiments across rice growing irrigated areas in India. Due to ambiguity in nomenclature of some locations in the initial years, data from 159 experiments were removed before analyses. Grain yield assessments were done on hybrid genotypes for only 1-4 years in 270 experiments performed and were omitted as inadequate for analysis ${ }^{12}$. Boyles et al ${ }^{18}$ had also excluded data from locations that were not represented for five or more years from the long-term analysis of red wheat experiments. The remaining assessments were done for 5-24 years. In 962 experiments, hybrid $F_{1}$ genotypes had produced yields lower than that of inbred LCV in one or more trials. Thus, nearly two-thirds of all experiments performed had demonstrated the lack of hybrid vigor in hybrid $F_{1}$ genotypes evaluated. This is a colossal loss of efforts at 102 locations on field evaluation, time and money used to

Page 15/32 
conduct these experiments made with hybrid $F_{1}$ genotypes from 1988-2019 (Additional file 1, Table S1). Initiation of an additional singular trial for hybrids with medium slender grains from the year 2006 further demonstrated the speculative organization of testing in METs of AICRIP as early, mid-early and medium maturing hybrid $\mathrm{F}_{1}$ genotypes with this grain type were already available in adequate quantities (Additional file 4: Table S2). The limited use of released 10 commercial hybrids from 2005 as checks (Table 8) further confirmed the difficulty of producing and supplying hybrid seed in sufficient quantity for tests. However, 54 inbred checks have been used with frequent and rather irrational replacements. Astoundingly, while high yields ( 9 t/ha) were recorded in ILCV in some experiments, at most locations (Additional file 6, Table S4) but the ILCVM remained low ( $6 \mathrm{t} / \mathrm{ha}$ ). Apparently there was no attempt to select an appropriate inbred variety for use as check. Our analysis further adds to doubts raised by Muralidharan et $\mathrm{al}^{7,9}$ that either the yield of inbred local check is underestimated or the yield of hybrid $F_{1}$ genotype is over estimated. The lack of required repetitions of experiments has made the bulk of resource and efforts on assessment of grain yields of expensive hybrid $F_{1}$ genotypes irrelevant. There was evidently no critical assessment of the data on hybrid rice experiments in AICRIP from time to time.

\section{Critical appraisal of test locations for evaluation of hybrid rice}

For commercial release of a hybrid genotype, the criterion set is the ability to produce at least $10 \%$ higher grain yield than the inbred check due to heterosis ${ }^{3}$. During 1996-2019, rice hybrid $F_{1}$ genotypes were tested at 102 test locations in the irrigated ecosystem in four trials across India. The mean grain yields produced by hybrid $F_{1}$ genotypes were higher than the yields harvested in ILCV at 30 locations (13 AICRIP, 11 private and 6 voluntary) (Tables 4-7). The coefficient of variation (CV) is a standardized, dimensionless measure of dispersion relative to a data set's average. It enables the comparison of several data sets on genotypes ${ }^{19}$. It is also used as a measure to compare the robustness of different biological traits ${ }^{20}$. At locations where heterosis in yield was detected in hybrid $F_{1}$ genotypes, the $C V$ remained low (10 to $11 \%$ ) indicating robustness of analysis. Only 23 locations, hybrid $F_{1}$ genotypes recorded $\geq 10$ per cent higher grain yields than that of ILCV. These locations revealing such heterosis in hybrids are 8 public funded AICRIP locations at Coimbatore (Tamil Nadu), Karnal and Kaul (Haryana), Kapurthala and, Ludhiana (Punjab), Mandya and Mugad (Karnataka) and Warangal (Telangana); 11 private funded locations at Advanta, Bayer, Bio Seeds, HR International, Kaveri Seeds, Mahyco Seeds, Nuziveedu Seeds, Pan Seeds, Parry Monsanto, Syngenta India and VNR Seeds; and 4 voluntary locations at Allahabad (Uttar Pradesh), Gaddipally (Telangana State), Jabalpur (Madhya Pradesh) and Karaikal (Puducherry) in India. Although hybrid $\mathrm{F}_{1}$ genotypes have been tested and shown to produce higher yields at locations in the states of Andhra Pradesh, Karnataka, Haryana, Puducherry, Punjab, Tamil Nadu and Telangana State, commercial hybrids are grown only in Uttar Pradesh. The yields of hybrids were much less than those of inbreds at all the test locations in Bihar, Chhattisgarh and Jharkhand. The locations for testing hybrid $F_{1}$ genotypes were evidently not selected based on the merit of execution of experiments. Periodical and critical examinations of testing programs are necessary as they can save cost incurred by human resource and infrastructure, and can free scientists for deployment in other activities. The irrational choice of locations makes hybrid rice experiments a wasted exercise and precludes any diffusion of technology developed due to exclusion of bulk of the potential target area.

Hybrid rice cultivation has been estimated to cover 1.5-2.0 million ha mainly in the Indian states of Bihar, Chhattisgarh, Jharkhand and Uttar Pradesh ${ }^{21}$. Monetary incentives are provided by the Government of India for the training, production and distribution of hybrid seeds by public organizations and private seed business firms. Jharkhand is rainfed and has a limited irrigated area (<5\%). By contrast, 8.51 million ha irrigated area in Bihar (2.13 m ha), Chhattisgarh (1.34 m ha) and Uttar Pradesh (5.04 $\mathrm{m} \mathrm{ha}$ ) are available for growing hybrid rice. Yield assessment of hybrid genotypes may be performed in future at select locations in these target areas to avoid wastage of resources, improve efficiency and overcome the difficulty of short supply of hybrid seeds.

\section{Legitimacy of hybrid trials}

Hybrid $F_{1}$ genotypes, inbred checks and commercial hybrid varieties have been organized into four trials with IHRT-E (early 110-120 days), IHRT-ME (mid-early 121-130 days), IHRT-MED (medium maturity 131-140 days), and IHRT-MS (medium slender 
grains maturing in $130 \pm 5$ days). Our analyses have shown the presence of medium slender grain types in the hybrid genotypes included in these trials in nearly equal numbers. Therefore, the IHRT-MS is redundant. The productivity per day was comparatively higher in early and mid-early maturing than medium maturing commercial hybrids or ILCV (Tables 4-6).

China has so far cultivated only commercially released hybrids that have a long maturity duration (>140 days).Yuan and Sun ${ }^{22}$ had reported on the development of an early maturing hybrid Weiyou 64 . The compatibility of early maturity and high yield in rice has been a subject of debate ${ }^{23}$. Using the early-maturing restorer line Ce64 derived from IR9761-19-1, Minghui $77^{24}$, Zaohui89 $9^{25}$ and other early maturing hybrids were developed in China. Mapping of a dominant earliness gene, Early flowering-completely dominant ( $E f$-cd) encoding a long noncoding RNA (IncRNA) ${ }^{26}$ and its subsequent cloning ${ }^{27}$ have revealed the genetics behind the possibility of exploring this trait to combine early maturity and high yield for enhancing productivity per day. High-yielding rice hybrids in China usually take 160 to even 180 days from sowing to harvest. The newly developed early maturing (125 days) hybrid variety G3-1S/P19 tested at two sites produced $1.57 \mathrm{~kg} / \mathrm{m}^{2}$ in central China's Hunan Province ${ }^{28}$. Several high yielding early maturing inbred commercial varieties have been developed in India ${ }^{29}$ and elsewhere, unconscious of the earliness gene $(E f$ - $c d)$, based on simple phenotype selection ${ }^{30}$. We have demonstrated that early (110-120 days) and mid-early maturing (121-130 days) hybrid $F_{\mid}$genotypes produce high yields ( 7 to $\left.8 \mathrm{t} / \mathrm{ha}\right)$ with increased productivity per day (61-63 kg/ha). As the maturity duration is increased, water requirement, the cost of cultivation and the associated risks also increased. A scrutiny of AICRIP data indicated that most hybrid $F_{1}$ genotypes matured between 115 and 135 days. Therefore, efforts may be more focused to breed early and mid-early maturing hybrids with high productivity per day.

\section{Hybrid vigour and its exploitation}

Hybrid genotypes had produced higher yields by $728-2588 \mathrm{~kg} / \mathrm{ha}$ than the yields of inbred LCV (4922-5648 kg/ha) at only 30 locations tested in 5-24 experiments (Table 4-7). None of the hybrids evaluated for 32 years had shown a mean yield of $\geq 10$ t/ha that has been long-established repeatedly with inbred LCV in METs of AICRIP7,9,11,31. Yet, the grain yields of 7.0 to 7.9 $\mathrm{t} /$ ha in hybrid genotypes attained in many experiments reveal the achievable higher yield owing to unhindered and better crop husbandry. This inference is confirmed by the lack of genetic gain for grain yields of hybrids in any of the trials examined in this study. The claim of heterosis can deceptively come from an under-estimation of inbred LCV, especially when inbred yields are as low as 5-6 t/ha as compared with their easily attainable level of $\geq 10 \mathrm{t} /$ ha under efficient crop management. Heterosis is considered as an important trait to increase biomass and yield in hybrid $\mathrm{F}_{1}$ genotypes than in the specific parents used, but not over the yield of commercially cultivated high yielding inbred varieties. Rice-breeding using abundant and variable germplasm accessions for many decades has effected countless - and often unknown - changes in the genetic composition of inbred varieties. Breeding activity however, is solely dependent on the meager availability of male sterile lines to develop hybrid rice varieties. The genetic basis of heterosis is less understood ${ }^{32}$. The recent advancements in cloning the heterotic QTL GW3p6 and development of a near-isogenic rice line indicate the possibility of realizing high yield in inbred rice lines without even needing to develop hybrid rice ${ }^{33}$.

\section{Unsettled issues}

Breeding hybrids has demonstrated improved yield potential in many cross-pollinated crops such as sorghum, maize and cotton ${ }^{34,35,36}$. Hybrid breeding takes advantage of heterosis (hybrid vigour). It is a phenomenon where $F_{1}$ hybrids derived from crosses between genetically distinct inbred varieties exhibit superior phenotypic performance over their parents. Superior performance may specify an improved function of any biological process in the hybrid offspring ${ }^{37}$. Rice is a self-pollinated crop and commercial hybrid breeding mostly depends on a few cytoplasmic male sterile systems. It requires a lot of financial resource to evaluate field performance of all possible crosses among a large number of inbred lines ${ }^{38}$. In general, only a small proportion of crosses can be evaluated in the field and many potential superior crosses may not get tested. The evidence generated in our study has confirmed the production of the stipulated $10 \%$ more grains by some hybrids than what was produced by inbreds in many experiments. The grain yields recorded in these experiments however, were well below the 
attainable yield levels of inbreds established ever since 1968. The genuineness of the claim of a yield advantage in any hybrid over inbred variety is untenable. The optimized canopy, architecture, dark green leaves, erect flag leaf, narrow leaf, dwarf plants with a plant height of one meter, panicle length of $25 \mathrm{~cm}, 180$ grains per panicle, grain filling rate of $81 \%, 1000$-grains weight of $26 \mathrm{~g}$, and adaptability to a wide range of growing environments determine yield level of rice (data collected from 2013 2015 by China Rice Data Center, http://www.ricedata.cn/variety/varis/604222.htm) ${ }^{39}$. The architectural and physiological features associated with high yield were recently studied in two elite historical hybrid rice cultivars, i.e., YLY1 and LYP9 $^{39}$. The canopy photosynthesis was found to increase the proportion of biomass allocation to above ground tissues (1.5\%), productive tillers (25\%), photosynthate reserve in leaf sheath (5-11\%) before grain filling and photosynthate translocation to grains. Yet, the yields of hybrids have remained below or at best on par with the yield records of inbred varieties ( 10 t/ha).

A longer root, a larger number of tips, a better developed aerenchyma, a higher capacity for $\mathrm{N}$ uptake, and reduced $\mathrm{NH} 4^{+}$efflux from roots are associated with higher N-use efficiency and growth performance in hybrid super rice Yongyou 12 and Jiayou $6^{40}$. Lin et al ${ }^{41}$ used a linkage map consisting of high-density SNPs, to identify heterosis-associated five genes, which contributed to the high yield, with repeated occurrence of $q S S 7$ and $q H D 8$ in both hybrid populations. The two super hybrids Yongyou12 and Jiayou 6, however, produced grain yields of 11.0-11.8 t/ha compared to $9.1 \mathrm{t} /$ ha in common (inbred) variety Xiushui 134 at $200 \mathrm{~kg} \mathrm{~N} / \mathrm{ha}^{40}$.

The expression high yield of any variety is to be used in relation to the one that produces lower yield. However, whenever high yields of hybrids are reported, the yields of inbreds have been less than their demonstrated attainable yield. The question therefore, arises of whether the extra yield in the hybrid is due to heterosis? Is it only an assumption that the heterosis of hybrids developed leads to increased yields over inbreds? There is little evidence to indicate that heterosis of hybrids bred is due to induction of better traits in $F_{1}$ plants leading to enhanced yields. It is essential to prove that hybrids have certain improved traits compared with those of inbreds to produce more grain yields.

\section{Opportunities to achieve desirable heterosis for yield}

Dominance ${ }^{42}$ and overdominance ${ }^{43,44}$ hypotheses were coined long ago to explain heterosis. The molecular mechanism of heterosis still remains mysterious despite research on heterosis for more than a century. Unfolding research findings indicate the potential to improve heterosis by exploiting inter-specific heterosis between African rice and Asian rice ${ }^{45}$, differential expression of genes ${ }^{46}$, divergent selection and genetic introgression ${ }^{47}$, genomic hybrid breeding using whole genome markers ${ }^{48}$, epistasis interactions between select parents ${ }^{49}$, chromosome-segment substitution lines ${ }^{47}$, heterotic loci from wild Oryza longistaminata for yield heterosis ${ }^{50}$, wide compatible neo-tetraploid rice line with long panicles ${ }^{51}$ and genome wide transcriptome profiling of 0 . rufipogon ${ }^{52}$.

The hybrid performance in self-pollinated crops may depend on the initial strategy to form heterotic pools. Simulation studies of the future hybrid performance indicated an advantage in using heterotic pools only when there was high allelic diversity (number of quantitative trait nucleotides $\left(\right.$ QTN) $\geq 2000$ ) and/or high dominance at loci $(\geq 0.4)$ for a quantitative trait ${ }^{53}$. In 97 parental lines used with CMS line to produce Indian hybrids, Sruthi et al ${ }^{54}$ have reported limited diversity among and within the maintainer and restorer groups. Novel approaches of base-broadening before forming heterotic pool of QTNs and employing reciprocal recurrent genomic selection are expected to improve yield performance of hybrid breeding in selfpollinated crops like rice in future ${ }^{53}$.

\section{Stagnating yield in inbred varieties in breeders' experiments}

Absence of any genetic gain for grain yield has been demonstrated in successively generated inbred commercially released varieties compared to the early release of Indian semi-dwarf inbred varieties in 1968 by analyzing yield data from AICRIP 7,9 and from IRRI's international rice testing program ${ }^{11,31}$. Yields of major crops have stabilized or even stagnated in many regions of the world $31,55,56,57$. Any genetic gain of wheat, barley, rice and other cereal crops after 1967 is rightly attributed to 
modification of plant architecture, especially reduction in plant height, and the consequent non-lodging at high levels of nutrient application ${ }^{7}$ and increased harvest index and grains per unit area ${ }^{58}$. Nevertheless, AICRIP's progress in conventional breeding has added numerous traits of value in rice especially the ability to withstand abiotic and biotic stress conditions leading to enhanced stability in yield performance and overall production in the country. Improvements in the quality of grains of inbred varieties have enabled huge rice exports. Increases in national rice production have confirmed the continued improvement in crop production skills at the farm level along with effective use of irrigation, water-use-efficient varieties and other factors ${ }^{9}$. Inbred LCV had recorded overall mean grain yields ranging from 4.8 to $5.5 \mathrm{t} /$ ha (Table 2) in 2376 experiments across the country executed for 32 years along with hybrid $F_{1}$ genotypes. The mean grain yields produced by inbred LCV were low even at the best performing 20 locations ( 5.0 to $5.7 \mathrm{t} / \mathrm{ha}$ ). Nonetheless, the inbred check had shown high yields ranging from 9.1 to $9.8 \mathrm{t} /$ ha at several locations. Overwhelming evidence is available to indicate the stagnating grain yields of LCVs since the release of inbred variety Jaya that established $10 \mathrm{t} /$ ha as the easily realizable yield in 1968. A decisive introspection is warranted concerning crop husbandry practices that lead to low grain yields in inbred varieties compared to earlier records of high yields reported in support of their release. Unless the attainable yields are reached in inbred checks with appropriate crop production practices in an experiment, it is futile to make any comparison with new genotypes to estimate a genetic gain for grain yields.

\section{Dilemma in choosing inbred or hybrid variety}

Many indica and japonica hybrids have been cultivated in addition to inbred varieties in China. SY63 is a rice hybrid derived from the female parent Zhenshan 97 A (ZS97A, a WA CMS line) and the male parent MH63 in China ${ }^{59}$. The indica/japonica hybrid has more productive tillers, larger sink size, increased accumulation of non-structural carbohydrate in the stems at heading time and its remobilization to grains, higher enzyme activity for sucrose-to-starch conversion process in the grains, and greater photosynthesis during the ripening period; the hybrid has greater root biomass, deeper soil distribution at heading time, and higher root oxidation activity during the ripening period. Due to enhanced agronomic and physiological traits,

indica/japonica hybrid produces improved yields under low $\mathrm{N}$ input conditions ${ }^{60}$. Deng et $\mathrm{al}^{61}$ estimated potential yields of 8.6 to $10.8 \mathrm{t} / \mathrm{ha}$, while current farm yields varied from 5.2 to $8.8 \mathrm{t} / \mathrm{ha}$ across climate zones and rice systems in China. To ensure high yields, $\mathrm{N}$ fertilizer overdosing relative to actual needs is practiced by most rice farmers, especially in China. For example, approximately $50-90 \%$ of the $\mathrm{N}$ fertilizer is applied as a basal dressing, and the total $\mathrm{N}$ fertilizer input is as high as $270-330$ $\mathrm{kg} / \mathrm{ha}$ in Jiangsu Province, China ${ }^{62}$. These reports indicate that the estimated requirement is $27-33 \mathrm{~kg} \mathrm{~N} / \mathrm{t} \mathrm{grains}$. Averaged across 11 years (Hunan Province, China, from 2004 to 2014), grain yield and N requirements were $9.5 \mathrm{t} / \mathrm{ha}$ and $20.2 \mathrm{~kg} / \mathrm{t}$ or $192 \mathrm{~kg} /$ ha, respectively ${ }^{63}$. Application of $165 \mathrm{~kg} \mathrm{~N} /$ ha along with a plant density of $24-27 \times 10^{4}$ hills/ha significantly increased the grain yield in a widely cultivated hybrid Liangyou $3905^{64}$. Super hybrid rice varieties in China had achieved record high yields of $14 \mathrm{t} / \mathrm{ha}$ (Chaoyou1000) ${ }^{65}$ to $15 \mathrm{t} / \mathrm{ha}$ (YLY900) under optimal management conditions ${ }^{66}$. However, these high yield records occurred only in specific areas with adequate solar radiation, fertile soils and large differences between day and night temperatures etc ${ }^{67}$. Nitrogen requirement was calculated at $20 \mathrm{~kg} \mathrm{~N} / \mathrm{t}$ grains from a database covering a wide range of climatic conditions, soil types and field management across China ${ }^{68}$. At $270 \mathrm{~kg} / \mathrm{ha} \mathrm{N}$, the mean yield of japonica/indica hybrids was $12 \mathrm{t} / \mathrm{ha}$ (at $22.5 \mathrm{~kg} \mathrm{~N} / \mathrm{t}$ grains) and was higher than 9-10 t/ha yield of conventional rice ${ }^{69}$. Breeding green super rice varieties was pursued to obtain higher grain yield with less environmental impact. The average grain yield of green super rice varieties developed in China was more or less similar to that of super hybrid rice varieties ${ }^{70}$. Chang et al ${ }^{39}$ conducted experiments in three plots planted ( 150 hills at $0.2 \times 0.2 \mathrm{~m}$ ) with elite super hybrids YLY1 or LYP9. Fertilizer was supplied according to local standard agronomic practice for growing rice with $250 \mathrm{~kg} \mathrm{~N} / \mathrm{ha}, 150 \mathrm{~kg} \mathrm{P}_{2} \mathrm{O}_{5} /$ ha and $250 \mathrm{~kg} \mathrm{~K} \mathrm{~K}_{2} \mathrm{O} / \mathrm{ha}$. Grain yields from 50 hills were measured and used to derive the theoretical yield as 10-10.6 t/ha. The $\mathrm{N}$ required to produce one tonne grains was $24-25 \mathrm{~kg} / \mathrm{ha}$.

The theoretical yields calculated for super hybrids are closer to the estimates of national potential yield (9.8-10.5 $\mathrm{t} / \mathrm{ha})$ determined using the bottom-up approach ${ }^{61}$ and those using the top-down framework of Global Agro-Ecological Zone (GAEZ) protocols (IIASA-FAO 2012) ${ }^{71}$. Potential yield is a location-specific attribute as it depends on the crop growth duration and 
local weather. However, the current farm yield in China varied from 5.2 to $8.8 \mathrm{t} / \mathrm{ha}^{61}$. Huanghuazhan is the most common inbred rice cultivar planted in central and south China and is widely grown in 4.5 million ha across seven major rice-producing provinces (http://www.ricedata.cn/variety/) with high and stable yield, good quality, and wide adaptability. Although Huanghuazhan is an inbred cultivar, the yield is comparable to that of hybrid cultivars ${ }^{61,72}$. Therefore, it is clear that to harvest grain yields beyond $10 \mathrm{t} / \mathrm{ha}$ in hybrid super rice even in a limited area at select locations, adoption of intensive crop management and application of high levels of fertilizers and other input will be required. Rice grain yields of 10 to $11.6 \mathrm{t} / \mathrm{ha}$ in inbred varieties were recorded in yield trials performed at many locations in India 7,31 and in international trials across rice growing areas in many countries of the world ${ }^{11,31}$. Muralidharan et $\mathrm{al}^{9}$ further concluded that the potential yield is limited to 15-16 t/ha and attainable yield to 10-11 t/ha with choice inbred varieties in the best rice growing stress-free environment under intensive management. He et $\mathrm{al}^{73}$ estimated hybrid rice to yield $7.5 \mathrm{t} /$ ha when compared with $6.5 \mathrm{t} / \mathrm{ha}$ yields of inbreds in Jiangsu Province, China. From 1976 to 1995, hybrid rice varieties covering 15.7 million ha in China have yielded on an average $6.6 \mathrm{t} /$ ha compared with $5 \mathrm{t} /$ ha for conventional varieties ${ }^{74}$. Shanyou 63 (SY63), the most widely cultivated indica hybrid rice, had recorded $7325 \mathrm{~kg} / \mathrm{ha}$ in various regional, provincial and national yield trials from 1982 to 1985 . In spite of such yield reports, the increased grain production in China from 1984 to 2012 due to SY63 was estimated at an average yield increase of $300 \mathrm{~kg} / \mathrm{ha}$ over check varieties ${ }^{59}$.

$\mathrm{Li}$ et $\mathrm{al}^{75}$ had analyzed the data set on the performance of 7686 rice varieties generated by the government crop variety administration department of China from the 2-3 year-long regional trials performed from 1978 to 2017 at 10-20 test sites to study the relationship between yield and other agronomic traits. A scrutiny of (Supplementary Data Sheet 1 Trait values for the 7686 rice varieties studied, Table_1_Exploring the Relationships Between Yield and Yield-Related Traits for Rice Varieties Released in China From 1978 to $2017^{75}$ indicated that mean yields were 9.2 t/ha (4.6 to 12.4 t/ha) from 1809 japonica hybrids (156 days) compared to 8.7 t/ha (3.3 to 13.9 t/ha) from 296 japonica inbreds (153 days) ${ }^{75}$. The late maturing japonica (glutinous with low amylose content of $10-15 \%$ in grains or sticky rice) are grown in areas exposed to long days, and where grain filling continues for a longer period. Li et al ${ }^{75}$ further reported that the mean yields were $8 \mathrm{t} / \mathrm{ha}$ (3.8 to $\left.13.6 \mathrm{t} / \mathrm{ha}\right)$ from 4814 indica hybrids (132 days) compared to 6.7 t/ha (3.2 to 12.4 t/ha) from 767 indica inbreds (123 days). Our analysis of 2070 indica hybrid $F_{1}$ genotypes in trials of AICRIP performed in India from 1988-2019 also showed at 42 locations similar higher grain yields of 7.0 to $7.9 \mathrm{t} /$ ha in early (110-120 days), mid-early (121-130 days) and medium (131-140 days) maturing hybrid $F_{1}$ genotypes, and 5.8 to $7.6 \mathrm{t} /$ ha in those with medium slender grains ( $130 \pm 5$ days) as compared to 5.0 to $5.7 \mathrm{t} /$ ha in 583 indica inbreds (Tables 4-7). In all these yield trials of AICRIP, yields of inbred varieties were lower than their known attainable levels. None of the hybrids tested could match the mean grain yields of $\geq 10 \mathrm{t} / \mathrm{ha}$ recorded by indica inbred varieties such as Rasi, IR 36 and IR 50 (early 115-120 days), Jaya and IR 8 (medium 131-135 days), and Swarnadhan and Savitri (late maturing $>140$ days) in rice yield trials $s^{7,9,11,31}$. The inbred variety Pusa 44 is well known to produce grain yields of 7 to $8 \mathrm{t} /$ ha $^{29}$. It was released for commercial cultivation in 1994 and matures in 140-145 days. In 2017, a mid-early maturing green super rice (GSR) variety HHZ of China was released in Punjab as PR126. It matured in 123 days and yielded on par with the dominant variety Pusa 44 . The average productivity per day of PR126 was $61 \mathrm{~kg} / \mathrm{ha}^{76}$. In AICRIP experiments, a higher level of productivity per day ( 62 to $63 \mathrm{~kg} / \mathrm{ha}$ ) was recorded with the early maturing and mid-early maturing hybrid $\mathrm{F}_{1}$ genotypes at several locations and in many experiments (Tables 4-7). The $\mathrm{N}$ requirement to produce $8 \mathrm{t} / \mathrm{ha}$ of hybrid rice has been estimated at a minimum of $160 \mathrm{~kg} \mathrm{~N} / \mathrm{ha}$ or $20 \mathrm{~kg} \mathrm{~N} / \mathrm{t}$ in China ${ }^{68,69}$ compared to $120 \mathrm{~kg} \mathrm{~N} / \mathrm{ha}$ or $15 \mathrm{~kg} \mathrm{~N} / \mathrm{t}$ used in AICRIP experiments with hybrid genotypes across India. Elevating the expression or activity of NGR5 (nitrogen-mediated tiller growth response) in rice can possibly reduce nitrogen fertilizer use while increasing grain yields further ${ }^{77}$. Application of an optimum level of nitrogenous fertilizer can additionally reduce emission of nitrous oxide, a greenhouse gas that is 300 times more potent than carbon dioxide in affecting climate change ${ }^{78}$. Nitrogen use is inefficiently distributed spatially across global food systems ${ }^{79}$. India has a large population and a large yield gap in rice production $(\sim 6 \mathrm{t} / \mathrm{ha})^{9}$. The funds saved by reducing hybrid rice trials and test locations may be diverted to support sustainable intensification of rice production and research on precision farming and on increasing nitrogen use efficiency to reduce pollution. 
Incidence of diseases and pests were also documented on hybrid genotypes tested in AICRIP trials ${ }^{80}$. Genetic gains in terms of resistance to diseases and pests have been remarkable. Within a decade after the release of Jaya in 1968, rapid strides were made in the development of stable and widely adaptable varieties that were insulated with resistance against biotic and abiotic stresses ${ }^{7,29}$. The Indian varieties that produced stable high yields in the international tests, or those which possessed resistance to stresses or good quality traits found wide acceptance and claimed release in several countries around the world ${ }^{31,81}$. Genetic gain for resistance was amply proved when several AICRIP improved genotypes were shown to possess resistance ${ }^{7,81,82}$. Besides yield attributes, it is a simple task to incorporate genes possessing resistance to pathogens and insect pests in susceptible inbreds to achieve definite genetic gains. Although restorer lines with resistance genes are used to generate hybrids, little information is available on their full expression in hybrids. It is apparently easier to manage resistance and prevent yield losses from diseases and pests in inbreds than in hybrids. The emerging molecular understanding appears to indicate a metabolic conflict between heterosis and defense mechanisms. Down-regulation of defense response genes in hybrid has been reported to lead to heterosis ${ }^{83,84}$. Yields in hybrid seed production of the three-line system are still in the range of 1.5 to $2.0 \mathrm{t} / \mathrm{ha}$ in Asia ${ }^{85}$. Hybrid rice seed production requires adoption of appropriate but non-farmer friendly cultural practices and skilled labor at premium wages to ensure a good seed set, which ultimately increases the cost of $F_{1}$ seeds. Focus on increasing hybrid seed yield is needed. Apomixis, the asexual formation of seeds can be used by breeders to fix heterosis in hybrid seeds and rapidly generate doubled haploid crop lines to produce more hybrid seeds at a low cost. Using CRISPR/Cas9 gene editing technology, synthetic apomixis was established, but it reduced the numbers of clonal seeds produced $^{86}$. This uneconomical and scanty hybrid seed production forces the Government of India to provide a massive financial support for training, production and distribution of hybrids seeds by public organizations and private seed business

firms ${ }^{87}$. Yet, due to easy availability and much less price of seeds, farmers would undoubtedly prefer to grow high yielding inbred commercially released rice varieties to reduce the production cost. We have demonstrated that at the same level of cultural and agronomic management from 1988-2019, hybrid $F_{1}$ genotypes with different maturity periods produced yields that are comparable or less than inbred LCV in 1391 experiments; in 985 experiments hybrid $F_{1}$ genotypes produced yields that are $\geq 10 \%$ higher than yield of inbred varieties. Further, records on high yields of 10-13 $t /$ ha in hybrid $F_{1}$ genotypes and 9 $10 \mathrm{t} / \mathrm{ha}$ in inbred varieties at many experiments beyond doubt proves the need to use efficient agronomic management practices in rice production to acquire higher yield benefits.

\section{Conclusions}

We analyzed the rice grain yield data of 2070 hybrid $F_{1}$ genotypes with inbred varieties evaluated over 32 years (1988 to 2019) in 2376 multi-environment experiments executed at 102 locations in the irrigated ecosystem across India. The genetic gain or loss in yield of hybrid $F_{1}$ genotypes estimated in tests over years was non-significant. Hybrid $F_{1}$ genotypes produced grain yields of 7.0 to $7.9 \mathrm{t} / \mathrm{ha}$, which matched with the yields of hybrids and green super rice reports from China. India-bred hybrids showed higher productivity per day (62 to $63 \mathrm{~kg} / \mathrm{ha}$ ) and shorter maturity periods than super hybrids of China. The $\mathrm{N}$ requirement to produce $8 \mathrm{t} / \mathrm{ha}$ of hybrid rice grains was $15 \mathrm{~kg} \mathrm{~N} / \mathrm{t}$ as compared with a minimum of $20 \mathrm{~kg} \mathrm{~N} / \mathrm{t}$ used in China. Hybrids and inbreds produced grain yields that were easily attained with high yielding ( $\geq 10 \mathrm{t} / \mathrm{ha}$ ) commercial inbreds since 1968 , very similar to the yields reported from China. Only in less than $20 \%$ of test locations, hybrid $\mathrm{F}_{1}$ genotypes produced $10 \%$ more grains than the yields of inbred varieties. Yet, high yields of $9-10 \mathrm{t} /$ ha were recorded in yield trials with both inbred varieties and hybrids at many locations in India as reported from other rice growing areas in many countries of the world. Therefore, doubts arise on whether the yield of inbred local check is underestimated or the yield of hybrid $F_{1}$ genotype is overestimated. Further investigation is needed to find the reasons for the lower yields of inbred at these locations using uniform crop husbandry. Unless the attainable yields ( $\geq 10 \mathrm{t} / \mathrm{ha}$ ) are reached in inbred checks with the proven appropriate crop production practices in an experiment, it is futile to estimate a genetic gain or loss for grain yields in new genotypes developed. Opportunities still exist to breed more heterotic early and mid-early maturing hybrids, and develop efficient agronomical practices to realize the potential advantages from hybrids. The presence of definite improved traits must be demonstrated in hybrid $\mathrm{F}_{1}$ genotypes before making any comparison with inbred varieties to produce more grain yields. There is scope for breeders to limit test locations to represent specific target areas to avoid data loss. Focusing on removing

Page 21/32 
technical barriers in hybrid seed production is essential to exploit yield heterosis in hybrids, and to make hybrid rice technology profitable to farmers.

\section{Methods}

\section{METs of hybrid genotypes and data sets on grain yield}

As many as 2070 hybrid $\mathrm{F}_{1}$ genotypes in Initial Hybrid Rice Trials (IHRT) were evaluated in METs of AICIRP for 32 years ${ }^{5}$. Hybrid $F_{1}$ genotypes were grouped depending on the maturity duration and grain type into four different trials: IHRT-E (early maturing -110-120 days), IHRT-ME (mid-early maturing - 121-130 days), IHRT-MED (medium maturing - 131-140 days) and IHRT-MS (medium slender grains maturing in $130 \pm 5$ days). These experiments have led to the identification and release of 105 (36 public and 69 private seed industries bred) rice hybrids for commercial cultivation in India ${ }^{88}$. Data sets on grain yield assessment of hybrid $F_{1}$ genotypes along with inbred LCV in 2376 experiments executed between 1988 and 2019 were used for this study (Table 1). The ILCV were nationally released commercial inbred varieties grown widely at each test location. These experiments were performed in the irrigated fields at 102 locations in 23 states of India. Trials were conducted with different sets of hybrid $F_{1}$ genotypes each year belonging to early (IHRT E 110-120 days), mid-early (IHRT ME 121-130 days) and medium maturity (IHRT MED 131-140 days) durations. As Indian consumers predominantly prefer medium slender grain types, an additional trial (IHRT MS130 \pm 5 days) was introduced for this category in 2006 to identify such hybrid $F_{1}$ genotypes. In some years, one or the other trial was abandoned apparently due to paucity of hybrid genotypes or their seeds in adequate quantity.

All AICRIP's experiments were conducted in randomized block design with three replications. Every test hybrid $\mathrm{F}_{1}$ genotype was sown in nursery using 12-15 kg seeds/ha. In the irrigated ecosystem, 20-25-dayold seedlings were transplanted manually with a single seedling per hill in experimental plots, at a spacing of $20 \mathrm{~cm}$ between rows and $15 \mathrm{~cm}$ between hills. The experimental plot size varied with locations; but in most cases the minimum sub-plot size was $10 \mathrm{~m}^{2}$. Efforts were made at all locations to ensure crop growth of hybrid genotypes by adjusting the time of planting, and fertilizer application to suit the maturity period where a particular experiment was conducted. A basal dose of farm-yard manure at $10 \mathrm{t} / \mathrm{ha}$ was applied before ploughing the field and fertilizers were applied at a uniform rate (115 kg N:60 kg P $\left.\mathrm{O}_{5}: 60 \mathrm{~kg} \mathrm{~K} \mathrm{~K}_{2} \mathrm{ha}\right)$. The entire dose of phosphatic and potassic fertilizers together with one-half of the nitrogenous fertilizer were also applied as a basal dose in the last plough. The remaining nitrogenous fertilizer was applied in equal doses at maximum tillering and booting stages of crop growth. Appropriate recommended plant protection measures were used to control weeds, diseases and insects to prevent yield losses to the best possible extent. At the flowering stage, a dose of nitrogen ( $5 \mathrm{~kg} \mathrm{~N} / \mathrm{ha}$ ) was applied. In all treatment plots, one border row was excluded and grains from the remaining plants were harvested and expressed as $\mathrm{kg} / \mathrm{ha}$ at $14 \%$ moisture $e^{7,9,11}$.

\section{Assessment of genetic gain in hybrid $\mathrm{F}_{1}$ genotypes}

The methodologies employed for the yield assessment of hybrid $F_{1}$ genotypes in the irrigated ecosystem to coincide with the rice cropping season and crop management were approximately uniform. Individual trial data was scrutinized and analyzed by AICRIP at the end of each year. From the results presented by AICRIP for each trial over a period of 32 years ${ }^{5}$, the mean annual yields of the top-three hybrid genotypes (T3HM) were derived across all test sites. Similarly, ILCV mean yield and experimental mean (EXPM) yield estimated year-wise over locations were also derived and saved for later analysis. The estimates of T3HM, EXPM and ILCV are presented in data set 1 (Additional file 1, Table S1, sheet 1). The grain yields produced at 102 locations by cohorts of hybrid $F_{1}$ genotypes HYC and ILCV in experiments performed under four IHRT trials between 1996 and 2019 are given in data set 2 (Additional file 1, Table S1, sheet 2). Details on geographical position, soil conditions etc on the locations used are presented in Additional file 1, Table S1, sheets 3-4. The commercially released rice hybrids were used at locations from 2006 to 2019 as hybrid check variety (HCV) depending on $\mathrm{F}_{1}$ seed availability. Hybrid genotypes which consistently recorded more than $5 \%$ yield advantage over the HCV and $10 \%$ yield advantage over the inbred LCV were selected 
for commercial release. Details on the number of hybrid $\mathrm{F}_{1}$ genotypes, locations and experiments involved in this investigation are summarized in Table 1.

\section{Treatment of the yield data}

All the trials on hybrids were made in the irrigated ecosystem and with the use of cohorts of hybrid $F_{1}$ genotypes including checks each year and adoption of a set of agronomical practices recommended by the AICRIP 5 . Yet, the characteristics of locations and varying climatic conditions may exert some influence on the yields from year to year. To analyze the performance of yield or to identify genetic gain for yield in hybrid $F_{1}$ genotypes using available data from four different trials, it is crucial to remove the extraneous data or <noise > if any observed to the yearly variations in climatic and field conditions in locations. The methodology used was to choose a reference year and then to correct the yields step by step, based on the values over two consecutive years in the data set.

Let $Y_{m j}$ be the yield of the highest $j^{\text {th }}$ year, $j=1,2,3, \ldots . n$, and $Y$ be the grand mean.

$$
\begin{gathered}
Y_{\mathrm{m} 1 \mathrm{c}}=\sum_{\mathrm{n}}\left(\mathrm{Y}_{\mathrm{m} 1}+\overline{\mathrm{Y}}\right) / 2 \\
\mathrm{Y}_{\mathrm{mic}}=\sum_{\mathrm{j}=2}\left[\frac{\left(\mathrm{Y}_{\mathrm{mj}}+\mathrm{Y}_{\mathrm{m}(\mathrm{i}-1)}\right)}{2}\right]
\end{gathered}
$$

Thus "year effect" is calculated relative to the year $\mathrm{j}+1$, using the previously calculated "year effect" corrected yield value, and so on for all the years posterior to j, and identically for all the years anterior to $\mathrm{j}$. In the data set 1 , the year variable for T3HM, EXPM and ILCV (Additional file 1, Table S1, sheet 1) is corrected with the calculated respective grand means, $\mathbf{Y}_{\text {mt3h }}, \mathbf{Y}_{\text {mexp }}$ and $\mathrm{Y}_{\text {milcv }}$, for these three floating checks. For the data set 2 (Additional file 1, Table S1, sheet 2), grand mean yield of locations over years, $\mathrm{Y}_{\mathrm{mly}}$ was calculated to make corrections. This process was followed for each of the four IHRT trials before any data analysis. Further, grain yield performance of HCV and ILCV in experiments was also tabulated ${ }^{5}$. Before analysing this data, individually the $\mathrm{Y}_{\mathrm{mhcv}}$ and $\mathrm{Y}_{\text {milcv }}$ were calculated for each hybrid rice trial, duration-wise to make corrections.

Analysis of variance of the mean grain yields derived over experiments (data set 1, Additional file 1, Table S1, sheet 1) at each of the locations was computed for each hybrid rice trial, duration-wise in the irrigated ecosystem ${ }^{12,89}$. Initially, the variances of mean grain yields in the T3HM, EXPM and ILCV were analyzed using the F-test. Wherever variance was homogenous, the data sets were pooled trial-wise. Mean comparisons were made for equality by $t$-test on the basis of analysis of variance. If variance was not homogenous, weighted means were derived. The mean grain yields of the top-three hybrid genotypes, inbred checks and hybrid breeding stock (experimental mean)that represent the hypothetical floating checks of Jensen ${ }^{6}$ adjust to yield gains, if any, annually. Instead of considering the top-most entry alone, the mean performance of the top-3 ranking hybrid genotypes provides a better measure of changes if any, in the genetic potential of successively developed new hybrid genotypes. For each test year in different hybrid trials, the mean grain yields of the three floating checks, T3HM, EXPM and ILCV, were calculated across locations. The linear regressions were performed with mean grain yields recorded by the three floating checks over the years, to estimate the change in yields due to genetic and environmental causes. Residual plots were evaluated for occurrence of visual pattern and coefficients of determination were calculated. In whichever trial the mean grain yields showed a statistically significant increase or decrease, genetic gain or loss was tested. To this end, in each test year under different trials, the yield of EXPM or ILCV was deducted from the grain yield of T3HM to eliminate the environmental effect, and regression analyses were repeated to find genetic gain or loss, if any, for grain yield. The criteria used to identify the best-fit models were the significance of model parameters (Student's $t$-test), coefficients of determination $\left(R^{2}\right.$ and $R_{a}{ }^{2}$ that adjusts for the number of explanatory terms in model relative to the number of data points), and the lowest root means 
square of standard error (RMSE), while meeting the assumptions of normality, independence and homogenous variance in regression analysis ${ }^{90,91,92}$.

To assess the performance of hybrid genotypes at locations, the number of experiments performed to test hybrid genotypes in different maturity groups in AICRIP experiments performed between 1996 and 2019 were tabulated (Table 1). The mean grain yields of cohorts of hybrid $\mathrm{F}_{1}$ genotypes, HCV and inbred LCV recorded in the experiments at each test location were culled and assembled in each trial for each location year-wise. ANOVA was performed ${ }^{12}$ by considering all experiments made in various years at each of the locations. Further, grain types of rice hybrid genotypes in the four IHRT trials evaluated between 1996and 2019 were tabulated $5,93,94$.

\section{List Of Abbreviations}

Cytoplasmic male sterile (CMS)

Indian Council of Agricultural Research (ICAR)

International Rice Research Institute (IRRI),

Top-three hybrid genotypes mean (T3HM),

Inbred local check variety mean (ILCVM)

Hybrid $F_{1}$ breeding stock or experimental mean (EXPM)

Hybrid commercial variety (HCV)

All India Coordinated Rice Improvement Project (AICRIP)

Multi-environment tests (METs)

IHRT Initial Hybrid Rice Trials,

IHRT-E early maturing

IHRT-ME mid-early maturing

IHRT-MED medium maturing

IHRT-MS medium slender grains

\section{Declarations}

\section{Acknowledgements}

We thank Late Dr. SVS Sastry, Former Project Director (AICRIP), ICAR- Indian Institute of Rice Research for early discussion on aspects of this study and critical comments. We also thank all the project coordinators, cooperating scientists from agricultural universities, private seed industries and voluntary research locations across India for the execution of AICRIP experiments from 1968 to 2019. This work is a personal research contribution of all authors.

\section{Authors contributions}

KM, GSVP and EAS conceived this research and mode of analysis. GSVP, CSR and KM performed data collection and creating Tables. CSR and KM executed statistical analysis. KM and RS wrote the manuscript with critical inputs from EAS. Manuscript was finalized by KM, RS and GSV for submission. All authors read and approved the final manuscript. 


\section{Funding}

ICAR-Indian Institute of Rice Research (IIRR) Hyderabad 500030, India.

\section{Availability of data and materials}

All data generated or analysed in this study are included in this published article and its additional files.

\section{Ethics approval and consent to participate}

Not applicable.

\section{Consent for publication}

Not applicable.

\section{Competing interests}

The authors declare that they have no competing interests.

\section{References}

1. Lin SS, Yuan LP (1980) Hybrid rice breeding in China. In: Innovative approaches to rice breeding, International Rice Research Institute, Manila, Philippines, 35-51.

2. Virmani SS, Edwards IB (1983) Current status and future prospects for breeding hybrid rice and wheat. Adv Agron 36:145214.

3. Yuan L, Virmani S (1988) Status of hybrid rice research and development. In: Hybrid rice. International Rice Research Institute, Manila, Philippines, 7-24, 1988.

4. Virmani SS, Aquino RC and Khush GS (1982) Heterosis breeding in rice Oryza sativa L. Theor App Genet 63:373-380.

5. ICAR-IIRR (1968-2020) Annual Progress Reports 1968-2019, All-India Coordinated Rice Improvement Project (AICRIP). ICAR-Indian Institute of Rice Research (formerly Directorate of Rice Research), Hyderabad 500030 India.

6. Jensen NF (1976) Floating checks for plant breeding nurseries. Cereal Res Commun 4:285-295.

7. Muralidharan K, Prasad GSV, Rao CS (1996) Breeding for rice improvement, where do we stand? Curr Sci 71: 438448. https://www.currentscience.ac.in/Downloads/article_id_071_06_0438_0448_0.pdf

8. Meridth Jr, Bridge RR (1984) In: Genetic contribution to yield gains of five major crop plants. Crop Sci Soc Am Spl Publ 7:75-87.

9. Muralidharan K, Prasad GSV, Rao CS, Siddiq EA (2019) Genetic gain for yield in rice breeding and rice production in India to meet with the demand from increased human population. Curr Sci116:544-560.doi: 10.18520/cs/v116/i4/544-560

10. IRRI (1976-1998) International Rice Research Institute, Annual Final Reports. International Rice Testing Program (IRTP) or, International Network for Genetic Evaluation of Rice (INGER), Philippines.

11. MuralidharanK, Prasad GSV, Rao CS (2002) Yield performance of rice genotypes in international multi-environment trials during 1976-97. Curr Sci83:610-619. https://www.currentscience.ac.in/Downloads/article_id_083_05_0610_0619_0.pdf

12. Gomez KA, Gomez AA (1982) Statistical procedures for agricultural research with emphasis on rice. International Rice Research Institute, Philippines.

13. 13.Virmani SS, Siddiq EA, Muralidharan K, editors. 1998. Advances in hybrid rice technology. Proceedings of the 3rd International Symposium on Hybrid Rice, 14-16 November 1996, Hyderabad, India. Manila (Philippines): International Rice Research Institute. 443 p. http://books.irri.org/9712201155_content.pdf

14. Xie F, Hardy B (eds) (2012) Public-private partnership for hybrid rice. 6th International Symposium on Hybrid Rice, 10-12 September 2012, Hyderabad, India. International Rice Research Institute, Los Baños, Philippines. 
15. Kang MS (1988) A rank-sum method for selecting high-yielding, stable corn genotypes. Cereal Res Commun 16:113-115.

16. Eskridge KM (1990) Selection of stable cultivars using a safety-first rule. Crop Sci 30:369-374.

17. Grausgruber H (2012) Performance stability. Breeding methodology and quantitative genetics. University of Natural Resources and Life Sciences, Vienna. https://docplayer.org/82921455-Leistungsstabilitaet-heinrich-grausgruberzuchtmethodik-und-quantitative-genetik-ue-h-grausgruber-universitaet-fuer-bodenkultur-wien.html. http://plantbreeding.boku.ac.at/957321/2018/01_HG_Stability.pdf. Accessed November 10, 2020.

18. Boyles RE, Marshall DS, Bockelman HE (2019) Yield data from the uniform southern soft red winter wheat nursery emphasize importance of selection location and environment for cultivar development. Crop Sci 59:1887-1898.

19. Ospina R, Marmolejo-Ramos F (2019) Performance of some estimators of relative variability. Front Appl Math Stat 21 August 2019. https://doi.org/10.3389/fams.2019.00043

20. Félix MA, Barkoulas M (2015) Pervasive robustness in biological systems. Nat Rev Genet 16:483-96. doi: $10.1038 / \mathrm{nrg} 3949$

21. Viraktamath BC, Prasad ASH, Ramesha MS, Senguttuvel P, Revathi P, Raju KBK (2012) Hybrid rice research and development in India. In: Xie F, Hardy B (eds) Public-private partnership for hybrid rice. 6th International Hybrid Rice Symposium, 10-12 September 2012, Hyderabad, India, International Rice Research Institute, Los Baños, Philippines. pp 19-37.

22. Yuan LP, Sun MY (1984) New hybrid rice variety Weiyou 64. (In Chinese) Bull Agric Sci Technol 5:1-2.

23. Wang W, Hu B, Yuan D, Liu Y, Che R, Hu Y, Ou S, Liu Y, Zhang Z, Wang H, Li H, Jiang Z, Zhang Z, Gao X, Qiu Y, Meng X, Liu Y, Bai Y, Liang Y, Wang Y, Zhang L, Li L, Sodmergen, Jing H, Li J, Chu C (2018) Expression of the nitrate transporter gene OsNRT1.1a/OsNPF6.3 confers high yield and early maturation in rice. Plant Cell 30:638-

651.https://doi.org/10.1105/tpc.17.00809

24. Wu FX, Zhang JT, Xie HA. (2012) Application of indica hybrid rice restorer line Minghui77. Fujian J Agri Sci 27:773-779.

25. Wang NY, Liang KJ, Chen QJ, Chen SH Chen QH, Yang RC (1996) The development of early indica hybrid rice Shanyou 89. J. Fujian Agric. Univ. 25,400-404.

26. Deng XJ, Zhou KD, Li RD, Chun Z, Li P, Wang WM, Zhai WX, Zhu LH (2001) Identification and gene mapping of completely dominant earliness in rice (Oryza sativa L). Sci Agric Sin 34:233-239.

27. Fang J, Zhang FT, Wang HR, Wang W, Zhao F, Li ZJ, Sun CH, Chen F M, Xu F, Chang SQ et al (2019) Ef-cd locus shortens rice maturity duration without yield penalty. Proc Natl Acad Sci USA 116:18717-18722.

28. Yuan L (2019) China Focus: Third-generation hybrid rice achieves high yields in China. http://www.xinhuanet.com/english/2019-10/22/c_138494039_2.htm(2019). Accessed November 10, 2020

29. Rani NS, Prasad GSV, Rao LVS, Sudharshan I, Pandey M, Babu R, Ram T, Padmavati G, Muralidharan K, Pasalu IC, Viraktamath BC. (2008) High yielding rice varieties in India. Tech Bull 31:1-188. Indian Institute of Rice Research (Directorate of Rice Research), Hyderabad, India.

30. Yu Y, Qiam Q (2019) Rice breeding: A long noncoding locus with great potential. Mol Plant 12:1431-1433.

31. Prasad GSV, Muralidharan K, Rao CS (2001a) Stability and yield performance of genotypes: A proposal for re-grouping world rice area into mega environments. Curr Sci 81:1337-1346.

https://www.currentscience.ac.in/Downloads/article_id_081_10_1337_1346_0.pdfhttps://www.jstor.org/stable/24105850

32. Yang M, Wang X, Ren D, Huang H, Xu M, He G, Deng XW (2017) Genomic architecture of biomass heterosis in Arabdiopsis. PNAS 114:8101-8106.

33. Wang C, Tang S, Zhan Q, Hou Q, Zhao Y, Zhao Q, Feng Q, Zhou C et al (2019) Dissecting a heterotic gene through Graded Pool-Seq mapping informs a rice-improvement strategy. Nat Commun 10:2982.

34. Stephens J, Holland R (1954) Cytoplasmic male-sterility for hybrid sorghum seed production. Agron J 46:20-23.

35. Duvick DN (2001) Biotechnology in the 1930s: the development of hybrid maize. Nat Rev Genet 2: 69-74.

Page 26/32 
36. Khan NU, Hassan G, Kumbhar MB, Marwat KB, Khan MA, Parveen A and Saeed M (2009) Combining ability analysis to identify suitable parents for heterosis in seed cotton yield, its components and lint\% in upland cotton. Ind Crops Prod 29:108-115.

37. Stuber CW (1994) Heterosis in plant breeding. Plant Breed Rev 12:227-251.

38. Schrag TA, Mohring J, Melchinger AE, Kusterer B, Dhillon BS, Piepho H-P, Frisch M (2010) Prediction of hybrid performance in maize using molecular markers and joint analyses of hybrids and parental inbreds. Theor Appl Genet 120:451-461.

39. Chang S, Chang T, Song Q, Wu J, Luo Y, Chen X, Zhu XiG, Deng Q (2020) Architectural and physiological features to gain high yield in an elite rice line YLY1. Rice 13:60. https://doi.org/10.1186/s12284-020-00419-y

40. Chen M, Chen G, Di D, Kronzucker HJ, Shi W (2020) Higher nitrogen use efficiency (NUE) in hybrid "super rice" links to improved morphological and physiological traits in seedling roots. J Plant Physiol 251:153191.

https://doi.org/10.1016/j.jplph.2020.153191

41. Lin T, Zhou C, Chen G, Yu J, Wu W, Ge Y, Liu X, Li J, Jiang X, Tang W, Tian Y, Zhao Z, Zhu C, Wang C, Wan J (2020) Heterosis-associated genes confer high yield in super hybrid rice. Theor Appl Genet 133:3287-3297. https://doi.org/10.1007/s00122-020-03669-y

42. Davenport CB (1908) Degeneration, albinism and inbreeding. Science 28:454-455.

43. East EM (1908) Inbreeding in corn. Rep Conn Agric Exp Stn 1907: 419-428.

44. Shull GH (1908) The composition of a field of maize. J Hered 1:296-301.

45. Sun Y, He W, Xie Y, Zhao W, Tan J, Yang X, Dang T, Dong X, Xi K, Liu Y, Hu Y, Efisue AA, Jin D (2020) Exploiting interspecific heterosis between African rice and Asian rice. Crop Sci 60:2343-2353. https://doi.org/10.1002/csc2.20224

46. Katara JL, Verma RL, Parida M, Ngangkham U, Molla KA, Barbadikar KM, Mukherjee M, Parameswaran C, Samantaray S, Ravi NR, Singh ON and Mohapatra T (2020) Differential expression of genes at panicle initiation and grain filling stages implied in heterosis of rice hybrids. Int J Mol Sci 21:1080. doi:10.3390/ijms21031080

47. Lin Z, Qin P, Zhang X, Fub C, Dengd H, Fub X, Huang Z, Jiang S, Li C, TangX, Wang X, He G, Yuanzhu Yang Y, He H, Deng XW (2020) Divergent selection and genetic introgression shape the genome landscape of heterosis in hybrid rice. PNAS 117: 4623-4631. www.pnas.org/cgi/doi/10.1073/pnas.1919086117

48. Cui Y, Li R, Li G, Zhang F, Zhang Q, Ali J, Li Z, Xu S (2020) Hybrid breeding of rice via genomic selection. Plant Biotechnol J 18:57-67. doi: 10.1111/pbi.13170

49. Li H, Jiang S, Li C, Liu L, Lin Z, He H, Deng Z-W, Zhang Z, Wang Z (2020) The hybrid protein interactome contributes to rice heterosis as epistatic effects. Plant J (2020) 102: 116-128. doi: 10.1111/tpj.14616

50. Fan F, Long W, Liu M, Yuan H, Pan G, Li N, Li S (2019) Quantitative trait locus mapping of the combining ability for yieldrelated traits in wild rice Oryza longistaminata. J Agric Food Chem 67:8766-8772. DOI: 10.1021/acs.jafc.9b02224

51. Ghaleb MAA, Li C, Shahid MQ, Yu H, Liang J, Chen R, Wu J, Liu X (2020) Heterosis analysis and underlying molecular regulatory mechanism in a wide compatible neo-tetraploid rice line with long panicles. BMC Plant Biol 20:83. https://doi.org/10.1186/s12870-020-2291-z

52. Guttikonda H, Thummala SR, Agarwal S, Mangrauthia SK, Ramanan R, Neelamraju S (2020) Genome-wide transcriptomeprofle of rice hybrids with and without Oryza rufpogon introgression reveals candidate genes for yield. Sci Rep 10:4873. https://doi.org/10.1038/s41598-020-60922-6

53. Cowling WA, Gaynor RC, Antolín R, Gorjanc G, Edwards SM, Powell O, Hickey JH (2020) In silico simulation of future hybrid performance to evaluate heterotic pool formation in a self-pollinating crop. Sci Rep 10:4037.

54. Sruthi K, Divya B, Senguttuvel P, Revathi P, Kemparaju KB, Koteswararao P, Sundaram RM, Singh V, Kumar ER, Bhowmick PK, Vinod KK, Gopalakrishnan S, Singh AK, Prasad ASH (2020) Evaluation of genetic diversity of parental lines for development of heterotic groups in hybrid rice (Oryza sativa L.). J Plant Biochem Biotechnol 29:236-252(2020)

55. Acreche MM, Briceno-Felix G, Sanchez JA, Slafer. GA (2008) Physiological basis of genetic gains in Mediterranean bread wheat yield in Spain. Eur. J. Agron 28:162-170.

Page 27/32 
56. Sadras V, Lawson C (2011) Genetic gain in yield and associated changes in phenotype, trait plasticity and competitive ability of South Australian wheat varieties released between 1958 and 2007. Crop Pasture Sci 62:533-549.

57. Araus JL, Kefauver SC, Zaman-Allah M, Olsen MS, Cairns JE (2018) Translating high-throughput phenotyping into genetic gain. Trends Plant Sci 23:451-466.

58. Gracini P, Eskridge KM, Cassman KG (2013) Distinguishing between yield advances and yield plateaus in historical crop production trends. Nat Commun 4:2918.

59. Xie F, Zhang J (2018) Shanyou 63: an elite mega rice hybrid in China. Rice 11:17.

60. Chu G, Chen S, Xu C, Wang D, Zhang X (2019) Agronomic and physiological performance of indica/japonica hybrid rice cultivar under low nitrogen conditions. Field Crops Res 243: 107625. https://doi.org/10.1016/j.fcr.2019.107625

61. Deng N, Grassini P, Yang H, Huang J, Cassman KG, Peng,S (2019) Closing yield gaps for rice self-sufficiency in China. Nat Commun 10:1725.

62. Zhang F, Cui Z, Fan M, Zhang W, Chen X, Jiang R (2011) Integrated soil-crop system management: reducing environmental risk while increasing crop productivity and improving nutrient use efficiency in China. J Environ Qual 40:1051-1057.

63. Huang M, Chen J, Cao F, Zou Y, Uphoff N (2019) No-tillage effects on grain yield and nitrogen requirements in hybrid rice transplanted with single seedlings: Results of a long-term experiment. J Integ Agric 18:24-32.

64. Houa W, Khana MR, Zhanga J, Lua J, Rena T, Conga R, Lia X (2019) Nitrogen rate and plant density interaction enhances radiation interception, yield and nitrogen use efficiency of mechanically transplanted rice. Agric Ecosyst Environ 269:183-192.

65. Chen JX, Meng WD, Lin CS, Li JW, Peng YL, Fu CQ (2016) Performance and cultivation techniques of promising super hybrid rice combination Chaoyou1000 in the $6.82 \mathrm{hm}^{2}$ large demonstrative production at Sanya, Hainan. (In Chinese with English abstract). Hybrid Rice 31:40-42.

66. Li JW, Zhang YZ, Wu J, Lin S, Zhou PQ-Y, Deng Q-Y. (2014) High yielding cultural techniques of super hybrid rice YLY 900 yielded $15.40 \mathrm{t} / \mathrm{hm}^{2}$ on a $6.84 \mathrm{hm}^{2}$ scale. (In Chinese with English abstract). China Rice 20:1-4.

67. Liu K, Yang R, Lu J, Wang X, Lu B, Tian X, Zhang Y (2019) Radiation use efficiency and source-sink changes of super hybrid rice under shade stress during grain-filling stage. Agron J 111:1788-1798.

68. Che S, Zhao B, Li Y, Yuan L, Li W, Lin Z, Hu S, Shen B (2015) Review grain yield and nitrogen use efficiency in rice production regions in China. J Integ Agric 14: 2456-2466.

69. Xu D, Zhu Y, Chen ZF, Han C, Hu YJ, Qui S, Wu P, Liu GD, Wei H Y, Zhang HC (2020) Yield characteristics of japonica/ indica hybrids rice in the middle and lower reaches of the Yangtze River in China. J Integ Agric 19(10):2394-2406.

70. Huang L, Sun F, Yuan S, Peng S, Wang F (2018) Responses of candidate green super rice and super hybrid rice varieties to simplified and reduced input practice. Field Crops Res 218:78-87.

71. IIASA-FAO (2012) Global Agro-ecological Zones (GAEZ v3.0) (IIASA, Laxenburg, Austria and FAO, Rome, Italy, 2012.

72. Zhou, S. C. et al. (2008) Breeding and application of Huanghuazhan, a new early, middle or late rice variety with good quality and wide adaptability. J Agric Sci Technol 10:77-83.

73. He GT, Xigang Z, Flinn JC (1987) Hybrid rice production in Jiangsu Province, China. Oryza 24:297-312.

74. Yuan LP (1996) Hybrid rice breeding in China. In: Virmani SS, Siddiq EA, Muralidharan K, editors. 1998. Advances in hybrid rice technology. Proceedings of the 3rd International Symposium on Hybrid Rice, 14-16 November 1996, Hyderabad, India. Manila (Philippines): International Rice Research Institute. 443 p. http://books.irri.org/9712201155_content.pdf

75. Li R, Li M, Ashraf U, Liu S, Zhang J (2020) Exploring the relationships between yield and yield-related traits for rice varieties released in China from 1978 to 2017. Front Plant Sci 10: article 543.

https://www.frontiersin.org/articles/10.3389/fpls.2019.00543/full\#supplementary-material

Page 28/32 
76. Yu S, Ali J, Zhang C, Li Z, Zhang Q (2020) Genomic breeding of green super rice varieties and their deployment in Asia and Africa. Theor Appl Genet 2020. https://doi.org/10.1007/s00122-019-03516-9

77. Wu et al (2020) Enhanced sustainable green revolution yield via nitrogen responsive chromatin modulation in rice. Science 367:641 eaaz2046 (2020).

78. Tian H, Xu R, Canadell JG et al (2020) A comprehensive quantification of global nitrous oxide sources and sinks. Nature 585:248-256.

79. Wuepper, Clech SL, Zilberman D, Mueller N, Finger R (2020) Countries influence the trade-off between crop yields and nitrogen pollution. Nat Food 1:713-719. https://doi.org/10.1038/s43016-020-00185-6

80. ICAR-IIRR (1988-2020) National screening nursery. ICAR-Indian Institute of Rice Research (formerly Directorate of Rice Research), Hyderabad 500030 India.

81. Prasad GSV, Rao, UP, Rani, NS, Rao, L VS, Pasalu IC and Muralidharan K (2001b) Indian rice varieties released around the world. Curr Sci 80:1508-1511. https://www.currentscience.ac.in/Downloads/article_id_080_12_1508_1511_0.pdf

82. Muralidharan K, Krishnaiah K, Pasalu IC, and Venkateswarlu B (eds) (1987) Rice gall midge and its management. Directorate of Rice Research, Hyderabad 500030, India.

83. Smith LM (2019) Salicylic acid, senescence and heterosis. Plant Physiol 18:3-4.

84. Gonzalez-Bayon R, Shen Y, Groszmann M, Zhu A,Wang A, Dennis ES, Peacock WJ, Greaves IK (2019) Senescence and defense pathways contribute to heterosis. Plant Physiol 180:240-252.

85. Ali J, Paz MD, Marfori CM, Nicolas KL (2018) Environment sensitive genic male sterility (EGMS) based hybrid breeding in rice. In: Rao PV, Muralidharan K, Siddiq EA (eds) (2018) Molecular breeding strategies for crop improvement. pp120-142. One-day Dialogue, July 2017, Professor Jayashankar Telangana State Agricultural University (PJTSAU), Hyderabad, India. ISBN 978-81-936934-0-7.

86. Wang K (2020) Fixation of hybrid vigor in rice: synthetic apomixes generated by genome editing. aBIOTECH 1:15-20. https://doi.org/10.1007/s42994-019-00001-1

87. Government of India. Assistance for boosting seed production in the private sector. https://seednet.gov.in/Material/ProgSchemes.htm Accessed November 10, 2020.

88. Senguttuvel P, Revathi P, Kemparaju KB, Sruthi K, Ali SM, Rao KP, Hariprasad AS (2019) Rice hybrids released in India. Compendium No. 103/2019, 127. ICAR-IIRR, Rajendranagar, Hyderabad 500030 India.

89. Snedecor GW, Cochran WG (1967) Statistical Methods, Oxford \& IBH, New Delhi

90. Rao CR (1965) Linear Statistical Inference and its Applications, 2nd edn. Wiley, USA.

91. Neter J, Wasserman W, Kutner MH (1985) Applied linear Statistical Models. 2nd edn. Irwin, Homewood, IL, 1127p.

92. SAS Institute (1988) SAS users guide: Statistics, version 6.03 ed. SAS Institute, Cary, NC.

93. Ramaiah K (1985) Grain classification. In: Rice Research in India. 629p. Indian Council of Agricultural Research, New Delhi 110001.

94. Rani NS, Rao LVS, Viraktamath BC (2006) National guidelines for the conduct of distinctness, uniformity and stability: Rice. p 39. Directorate of Rice Research, Rajendranagar, Hyderabad 500030 India.

\section{Figures}




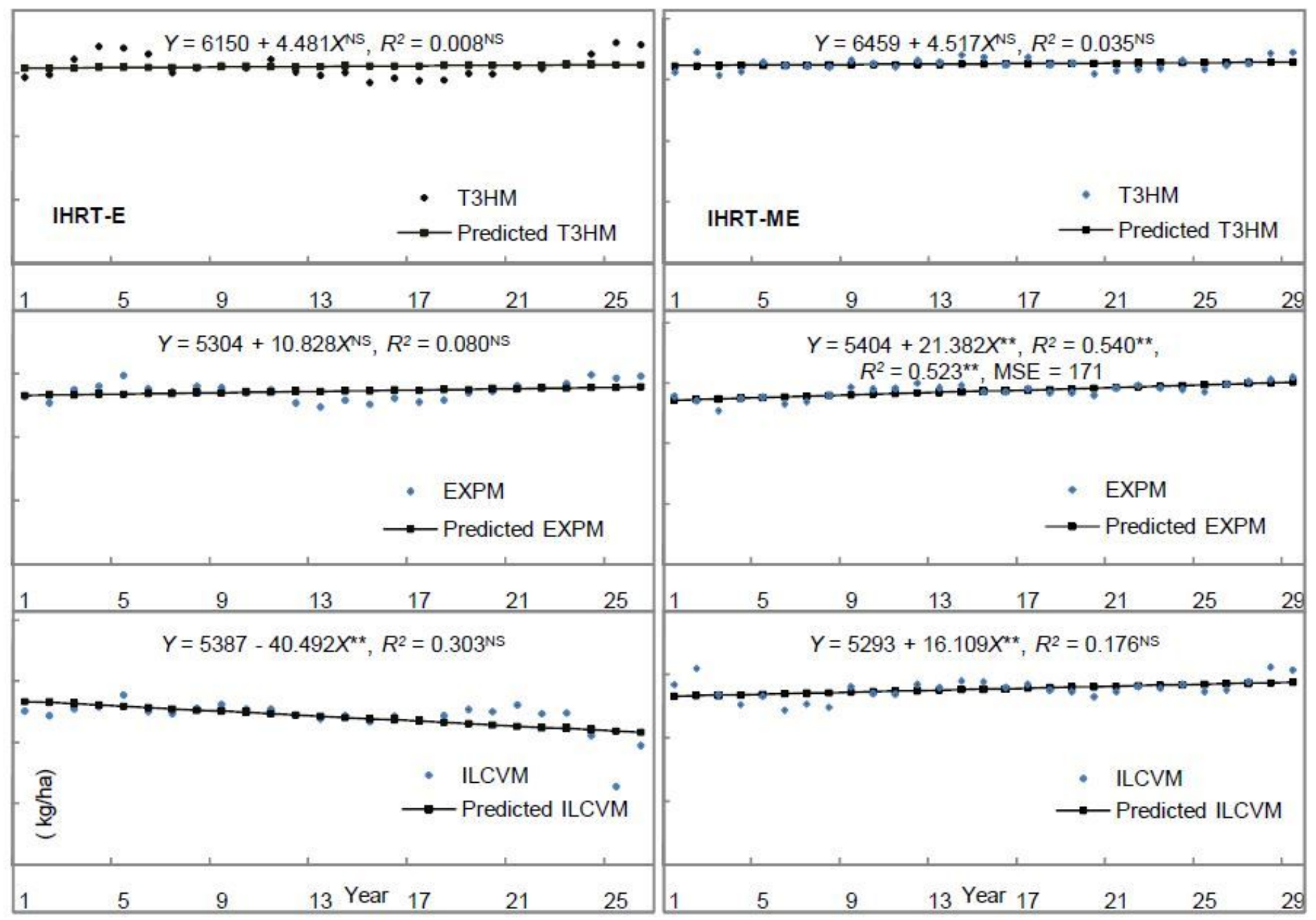

Figure 1

Grain yield performance of the three floating checks, T3HM, EXPM and ILCVM across locations in irrigated mega-environment over years and genetic gain or loss in yield. \# Source data are provided in Additional file 1: Table S1-Sheet 1. T3HM = top-three hybrid genotypes mean; EXPM = experimental mean; ILCVM = inbred local check variety mean. Left column represents IHRT-E (early maturity 110-120 days); right column represents IHRT-ME (mid-early maturity 121-130 days). Line fit represents the predicted mean grain yields. ${ }^{*} \mathrm{P}=0.05,{ }^{\star} * \mathrm{P}=0.01, \mathrm{NS}=$ non-significant. 


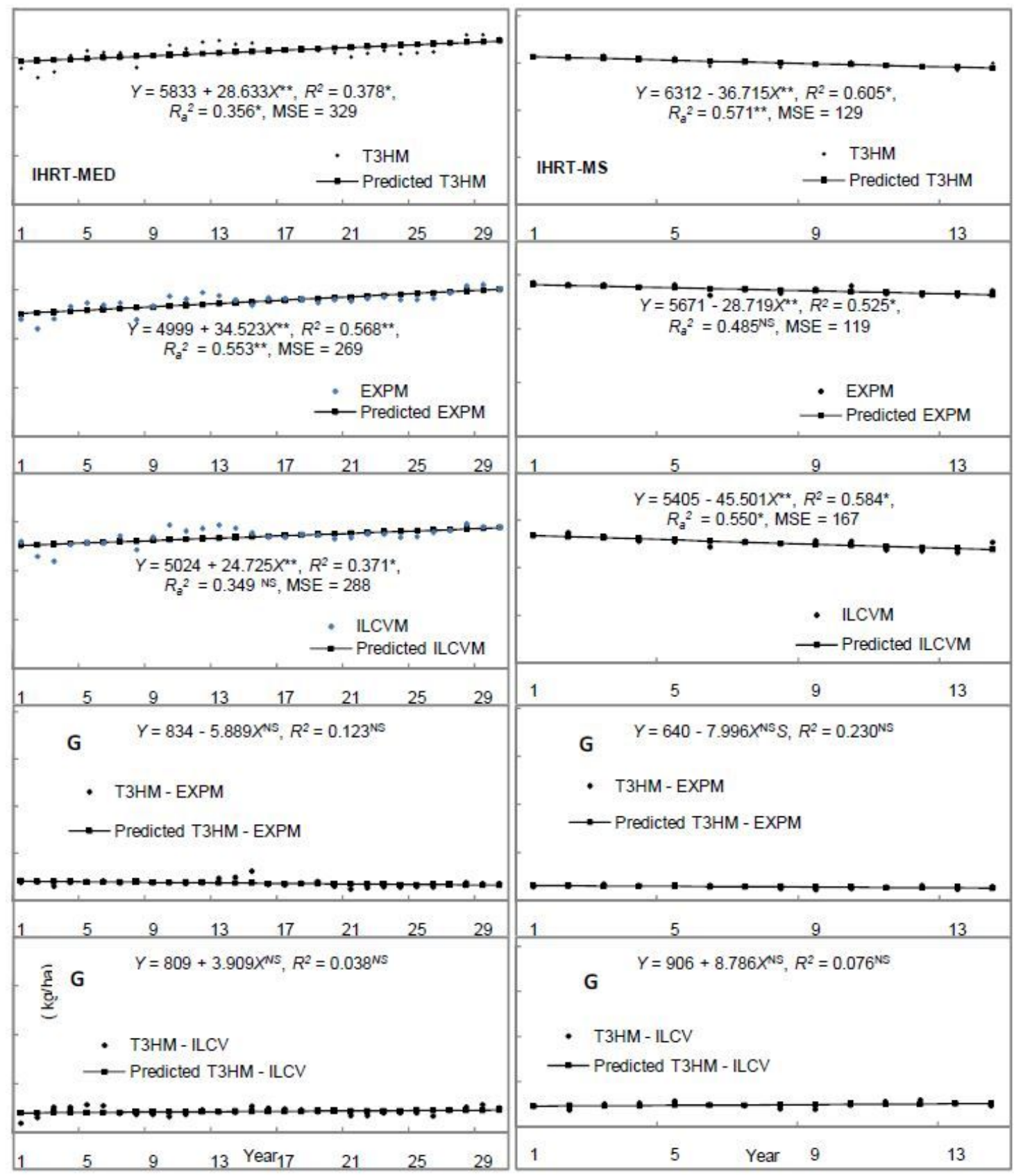

Figure 2

Grain yield performance of the three floating checks, T3HM, EXPM and ILCVM across locations in irrigated mega-environment over years and genetic gain or loss in yield. \# Source data are provided in Additional file 1: Table S1-Sheet 1. T3HM = top-three hybrid genotypes mean; EXPM = experimental mean; ILCVM = inbred local check variety mean Left column, IHRT-M (medium maturity 131-140 days) hybrids; and right column, IHRT-MS (medium slender grains, maturity in 130 \pm 5 days). Line fit represents the predicted mean grain yields. ${ }^{*} P=0.05,{ }^{*} \mathrm{P}=0.01, \mathrm{NS}=$ non-significant. $\mathrm{G}$, Genetic gain or loss in yield of hybrid genotypes derived by deducting EXPM or ILCVM yield from the T3HM grain yield to eliminate the environmental effect in repeated regression analyses.

\section{Supplementary Files}

This is a list of supplementary files associated with this preprint. Click to download.

- Additionalfile1TableS1.xlsx 
- Additionalfile3Figure2.pdf

- Additionalfile4Tables2.pdf

- Additionalfile5Tables3.pdf

- Additionalfile2Figure1.pdf

- Additionalfile6Tables4.pdf 